\title{
From Maize to Haze: Agricultural Shocks and the Growth of the Mexican Drug Sector*
}

\author{
Oeindrila Dube $\quad$ Omar García-Ponce ${ }^{\ddagger} \quad$ Kevin Thom ${ }^{\S}$
}

May 29, 2015

\begin{abstract}
Understanding how economic incentives affect illegal drug production is essential for crafting policies in response to the international drug trade. Policymakers typically face a choice between two strategies: targeting criminal groups via law enforcement, and offering producers incentives to engage in alternate activities. Yet, little is known about how the returns to alternate legal activities affect drug supply. We contribute to this literature by examining how shocks to legal commodity prices affect the drug trade in Mexico. Our analysis exploits exogenous movements in the Mexican maize price stemming from weather conditions in U.S. maize-growing regions, as well as exports of other major maize producers. Using data on over 2200 municipios spanning 1990-2010, we show that lower prices differentially increased the cultivation of both marijuana and opium poppies in municipios more climatically suited to growing maize. We also find impacts on downstream drug-trade outcomes, including drug cartel operations and killings perpetrated by these groups. Our findings demonstrate that maize price changes contributed to the burgeoning drug trade in Mexico, and point to the violent consequences of an expanding drug sector.
\end{abstract}

JEL Codes: K420, O13, Q17

\footnotetext{
${ }^{*}$ We are grateful to Chris Blattman, Konrad Burchardi, Michael Clemens, Arindrajit Dube, Joseph Kaboski, Nancy Qian, Craig McIntosh, Torsten Persson, Debraj Ray, Sendhil Mullainathan and participants at the Yale Development Seminar, UCSD Development Seminar, Berkeley Development Lunch, Barcelona GSE Summer Forum 2014, Princeton Political Economy Seminar, the Institute for International Economic Studies Seminar, the Harris School Political Economy Seminar, Stanford Comparative Politics Workshop, Stanford SITE Workshop on Governance and Development, the Kellogg Conflict and Cooperation Conference, the UPenn Conference on Crime in Latin America, LACEA-2013 and the U.S.-Mex Associates Conference, for highly valuable comments and suggestions. We also thank Viridiana Ríos and Michele Coscia for generously sharing their data. Dube gratefully acknowledges financial support from the Center for Global Development and from the America Latina Crime and Policy Network/CAF Development Bank. All errors are our own.
}

${ }^{\dagger}$ BREAD and New York University. Email: odube@nyu.edu.

${ }^{\ddagger}$ New York University. Email: garcia.ponce@nyu.edu.

$\S$ New York University. Email: kevin.thom@nyu.edu. 


\section{Introduction}

The international drug trade poses a multitude of challenges to security and the rule of law worldwide. Violence permeates the market, from brutal conflicts between international drug traffickers to street violence associated with retail drug dealing. Powerful criminal groups threaten to overwhelm local law enforcement institutions in regions as diverse as Latin America and Central Asia (Global Commission on Drug Policy 2011, USDS 2012). The violence surrounding this market highlights the importance of understanding the determinants of drug production, beginning with the cultivation of illicit crops.

Policymakers are confronted with two distinct approaches for curbing drug production. The law enforcement perspective focuses on the role of criminal organizations such as drug cartels. This approach prioritizes the prosecution of criminal groups and interdiction of drug supply. Indeed, Moore (1990, p. 134) observes that "A conventional theory is that supply-reduction efforts will be effective if only the major traffickers are arrested and successfully prosecuted."

An alternate perspective focuses on rural producers and their economic incentives to supply drug crops. This approach rests on the premise that drug production is subject to the same fundamental market forces driving output in other sectors. Consequently, the returns to alternative legal activities are held to play an important role in determining drug supply. In particular, the prices of legal crops are posited to influence household decisions to grow drugs via standard substitution and income effects. If this view is correct, there may be an important counter-narcotics role for policies aimed at rural households. These include price stabilization schemes and alternative development programs subsidizing the cultivation of legal crops.

Assessing the merits of these two policy approaches requires understanding how drug production responds to the legal alternatives available to farmers. Yet, relatively little is known about the behavior of rural producers supplying drugs. To examine this question, we study the effects of commodity price shocks on illicit crop production and drug war dynamics in Mexico. We focus on exogenous fluctuations in the price of maize, the nation's most important agricultural commodity. Mexico offers the ideal context for studying this question given the prevalence of drug cultivation and burgeoning drug war violence. Long the world's largest producer of marijuana, it recently became a leading player in the international heroin market (USDS 2011). Between 1990-2010, illicit crops were grown in over a third of all municipios. ${ }^{1}$ Violence also increased drastically during this time: over 50,000 drug-war killings occurred between 2007 and 2010 alone. $^{2}$

It is especially important to discern the impact of rural economic incentives on the drug trade in Mexico, where the law enforcement approach has dominated counter-narcotics efforts.

\footnotetext{
${ }^{1}$ Calculated on the basis of eradication data from the Mexican military (SEDENA), discussed in detail in Section 4.

${ }^{2}$ Calculated on the basis of data from the Mexican National Security Council, discussed in Section 4 .
} 
For example, the Calderón administration, which held office from 2006-2012, adapted a strategy of frontally attacking the drug cartels and dismantling their leadership. Many scholars have attributed rising homicide rates after 2007 to this policy (Guerrero 2010; Guerrero 2011; Merino 2011). The Mérida Initiative, a U.S. anti-drug aid package implemented in Mexico, also emphasizes the operational capacity of the cartels. As noted by a Congressional report, the vast majority of U.S. funds disbursed over 2008-2010 sought to break "the power and impunity of criminal organizations" (Seelke and Finklea, 2014, p. 6). Indeed, in both its joint ventures with the U.S. and its domestic programs, "[the] Mexican government has not traditionally provided support for alternative development" (ibid, p. 28).

To examine the relationship between maize prices and the drug trade, our empirical strategy exploits time variation in prices stemming from weather shocks in the United States Corn Belt, as well as the export behavior of other major players in this market. ${ }^{3}$ We also use crosssectional variation in the agro-climatic maize suitability of Mexican municipios. Combining these together via a difference-in-differences strategy, we determine whether maize prices exert larger impacts on municipios that are more suited to growing this crop. ${ }^{4}$

We construct a panel dataset of 2296 municipios over 1990-2010, and gauge the impact of price changes on a series of outcomes. We show that the sharp fall in maize prices during the 1990s led to differential increases in the cultivation of both marijuana and heroin poppies in more maize-suitable areas, as proxied by the eradication of these drug crops. Our estimates imply that the $59 \%$ fall in maize prices between 1990 and 2005 resulted in 12 percent more marijuana eradication and 4.7 percent more poppy eradication in municipios at the 90th percentile of the maize suitability distribution, as compared to municipios at the 10th percentile of this distribution.

In addition, our analysis uncovers effects further downstream along the narco-trafficking chain. For example, adverse maize price shocks lead to greater seizures of raw marijuana. These drug outputs are processed and transported to international markets by drug cartels, and violence may arise if cartels vie for control of these activities. Consistent with this account, we demonstrate a negative relationship between maize prices and cartel presence, as well as killings perpetrated by these groups over 2007-2010. These results show that price changes also affect the strategic decisions of cartels, which move into economically depressed territories where farmers are willing to supply illicit crops. Thus, policies aimed at rural cultivators may ultimately influence the operations of criminal groups.

\footnotetext{
${ }^{3}$ Note that we use the words maize and corn interchangeably to reference the same crop.

${ }^{4}$ Our empirical strategy is closely related to that of Nunn and Qian (2014), who use time variation in U.S. wheat production driven by weather conditions in the U.S. wheat region to examine the impact of food aid on conflict. It is also related to other studies that use cross-sectional variation in crop suitability, including Qian (2008) which utilizes variation in tea and orchard cultivation in China, and Nunn and Qian (2011) which focuses on variation in regional potato suitability.
} 
We conduct a number of checks to address potential threats to identification and demonstrate the robustness of these results. One concern is that eradication could be a misleading measure of production in the presence of endogenous enforcement. We show that our results are unaffected by controls for local enforcement, including arrests in government anti-drug operations and the mayor's political party, which shapes local drug-war policies (Dell forthcoming). Second, in an Appendix we develop and calibrate a model of optimal eradication policy. Our simulation results suggest that eradication serves as a good proxy for production, even in the presence of endogenously targeted enforcement.

We control for municipio-specific time trends, which alleviates concerns that divergent eradication tendencies across municipios of varying maize suitability confound our estimates. We also account for other factors that influence agricultural production. These include time-varying weather conditions, as well as land quality and suitability for growing other agricultural commodities, interacted with year effects. Finally, we use marijuana and poppy eradication at the outset of our sample period as a proxy for drug crop suitability, and control flexibly for these characteristics.

Our work contributes to the literature on drug cultivation and illicit production by studying how changes to legal alternatives influence these activities. The existing literature has primarily addressed the impact of enforcement-related shocks affecting the prices of illegal drugs themselves. Much of this work has focused on Colombia, examining how coca production and violence have responded to the disruption of cocaine transport out of Peru and Bolivia (Angrist and Kugler 2008) and greater cocaine interdiction by other countries (Mejia and Restrepo 2013). ${ }^{5}$

The few existing studies on the link between legal returns and drug outcomes have relied either on aggregate time-series variation or hypothetical survey experiments. For example, Moreno-Sanchez et al. (2003) find a negative relationship between plantain prices and coca production in Colombia, using time-series data. This strategy is potentially vulnerable to timevarying confounds, which we circumvent through our difference-in-differences strategy. ${ }^{6}$ Ibáñez and Carlsson (2010) and Ibáñez and Martinsson (2013) present evidence from experiments in

\footnotetext{
${ }^{5}$ The high cost of violence associated with Colombian drug production has been discussed by Mejia and Restrepo (2011), and potential spillover effects on Mexico have been documented by Castillo, Mejia and Restrepo (2013). The converse relationship, of how violence influences drug production in Afghanistan, is examined by Lind, Moene and Willumsen (forthcoming).

${ }^{6}$ In a study of civil war violence in Colombia, Dube and Vargas (2013) present a secondary result suggesting that coffee prices have no significant contemporaneous impact on detectable coca production. The little existing evidence on legal alternatives using observational data from Colombia is thus inconclusive. When comparing these results with our findings from Mexico, it is important to note that there are substantial differences in the illegal crops grown in the two countries. The leading drug crop in Colombia is coca, a perennial bush that requires three years to reach maturity. As such, coca production requires multi-year investments, and is less likely to smoothly respond to annual changes in the return to legal activities. In Mexico, we primarily observe marijuana and opium poppy production, which are annual crops that can be planted and harvested within a single year. The Mexican setting may thus provide clearer evidence on how legal returns affect incentives to engage in contemporaneous illegal activities.
} 
which rural producers in Colombia are asked how much coca they would cultivate in response to difference possible payoffs and production environments. These survey experiments suggest that hypothetical coca cultivation is not sensitive to the payoffs of alternate activities. Yet, no existing study traces out how changing legal alternatives influence observed behaviors along the entire narco-trafficking chain, from drug production to cartel activity and violence.

Our paper also contributes to the literature on the determinants of the drug war in Mexico. Despite the intensity of cartel-related violence in Mexico, the literature exploring its causes is relatively small. Dell (forthcoming) examines the role of enforcement policy, and shows that drug trade violence rises substantially in municipalities after the close election of mayors from the PAN political party. In particular, drug cartels contest areas in which incumbent traffickers have become weaker in the wake of crackdowns by PAN mayors. Our work is complementary in recognizing the importance of territorial contestation as a key element of rising violence. Durante and Gutierrez (2013) emphasize the role of inter-jurisdictional cooperation, and demonstrate that political alignment with mayors among neighboring municipalities reduces crime rates. Osorio (2012) focuses on another domestic political factor, analyzing the role of rising electoral competition. Dube et al. (2013) also show that access to guns from the United States have contributed to rising violence along the border. However, we are not aware of past work that has examined the role of economic shocks in shaping Mexico's drug war dynamics.

Our paper also relates to the literature on income shocks and conflict. Here studies have noted that higher income may increase conflict by promoting predation over resources (Hirshleifer 1991; Grossman 1999; Fearon 2005; Mitra and Ray forthcoming; Nunn and Qian 2011) or reduce it by increasing the opportunity cost of fighting (Becker 1968; Grossman 1991; Collier and Hoeffler 1998; Fearon and Laitin 2003; Miguel et al. 2004; Besley and Persson 2011; Do and Iyer 2010, Hidalgo et al. 2010, Gwande et al. 2012).

Similarly, studies on commodity prices and conflict also demonstrate that effects can be either negative or positive depending on the nature of the commodity. For example, the labor intensity of a commodity may influence the relative strength of the opportunity cost and predation channels (Dal Bó and Dal Bó 2011). In line with dominant opportunity cost effects, several studies report a negative relationship between export price indices and conflict (Brückner and Ciccone 2010; Berman and Couttenier 2013; Bazzi and Blattman 2014). ${ }^{7}$ In line with larger predation effects, others estimate a positive price and conflict relationship (Maystadt et al. forthcoming; Besley and Persson 2008 and 2009). Finally, Dube and Vargas (2013) show that both effects can operate in the same empirical setting: in Colombia, higher prices of labor intensive agricultural commodities reduce conflict, while higher prices of non-labor intensive

\footnotetext{
${ }^{7}$ The study by Bazzi and Blattman finds that falling commodity prices lower conflict intensity and duration, but not conflict outbreak.
} 
natural resources increase conflict.

Our findings differ from the existing results on commodity prices and conflict in two important ways. First, to the best of our knowledge, our paper is the first in this literature to study the effect of economic shocks on violence caused by organized criminal groups, or groups whose ultimate goals center on illegal production rather than regime change or the acquisition of political power. Drug cartels undoubtedly influence Mexican politics, whether through targeted killings and kidnappings, or through the support of allied politicians (Ríos and Shirk 2011). However, they do not seek to seize control of the state, like many of the groups studied in the existing literature. Our analysis thus connects economic shocks to a new and growing form of violence, which involves non-state actors fighting for profits in illegal markets rather than political power. These results are particularly relevant for weak states in which a substantial amount of economic activity is conducted outside the scope of legal markets.

Second, our analysis suggests a novel mechanism linking commodity price shocks with violence. Past work reporting a negative relationship between commodity prices (or income) and violence has typically pointed to a canonical opportunity cost mechanism. This account holds that decreasing opportunity costs fuel violence by increasing the pool of combatants or time spent on combat activities (Becker 1968; Grossman 1991; and Dal Bó and Dal Bó 2011). ${ }^{8}$ But for our empirical context, we posit that violence rises not from a larger number of combatants, but from the higher value of controlling territories adversely hit by price shocks. Under our account, a fall in local agricultural wages induced by price decline will increase the rents that cartels can extract from farmers supplying drugs in these territories. Consistently, our results demonstrate that changes in the outside options of local farmers influence both cartel location as well as drug-trade violence.

The remainder of the paper is organized as follows: section 2 provides institutional background; section 3 discusses the mechanisms that link maize prices and drug production; sections 4 and 5 describe our data and empirical strategy; section 6 presents our main results; section 7 addresses threats to identification; and section 8 concludes.

\section{Background}

This section provides background on two relevant aspects of the institutional context. First, we discuss the evolution of Mexico's drug trade. Second, we examine dynamics of the maize price over the course of our sample period.

\footnotetext{
${ }^{8}$ Esteban and Ray (2008) also show theoretically that one factor promoting ethnic conflict is the ease of forming within-group, cross-class alliances that pair conflict labor supplied by the poor with low-opportunity costs and financing from the rich.
} 


\subsection{The Mexican Drug War}

The Mexican drug trade increased sharply during the 1960s with rising demand for marijuana in the U.S., and grew further during the 1980s with rising demand for cocaine north of the border. During this latter period, Mexican and Colombian drug cartels began working together to traffic cocaine manufactured in South America (Astorga 2005, Toro 1995). Though initially sub-contractors for their Colombian counterparts, the Mexican cartels grew in power and by the 2000s dominated the drug distribution network. Simultaneously, the share of cocaine arriving to the U.S. via Mexico rose dramatically, from about 50 percent in the early 1990s to over 90 percent in the 2000s (O'Neil 2009).

Besides increased trafficking of South American cocaine, the growth of the Mexican drug trade has also been characterized by the production and distribution of home-grown drugs. Mexican cultivators grow both marijuana and opium poppies, which are used to manufacture heroin. While Mexico has long been a leading supplier of marijuana, it became an important supplier of heroin in the 1990s. Between 1993 and 2008, opium production increased more than six-fold, growing from a low base of 49 to 325 metric tons (USDS 2011). As of 2009, Mexico ranked as the world's third largest opium poppy supplier after Afghanistan and Burma.

Drug-trafficking violence was relatively restrained through the 1980s, but started rising in the 1990s, and ultimately skyrocketed in the 2000s. The stability of the 80s is attributed in part to underlying political conditions in Mexico. In the absence of political competition, the PRI political party consolidated patron-client relationships between drug traffickers, the police, and local elected officials. Implicit agreements with officials enabled some cartels to operate in particular locations with relative impunity, limiting in-fighting (O'Neil 2009). However, the entry of other political parties in local elections during the early 1990s undermined these arrangements (Bartra 2012, O'Neil 2009), incentivizing territorial expansion and inter-cartel fights (Osorio 2012). ${ }^{9}$

Continued cartel de-stabilization fueled further drug-related violence in the 2000s. In 2001, the leader of the Sinaloa cartel, Joaquín "El Chapo" Guzmán, escaped from prison and attempted to take over important drug routes near Texas and California. Violence subsequently increased in both the drug production areas and along the U.S.-Mexico border (Luhnow and de Cordoba 2009). Second, in December 2006, President Felipe Calderón launched an aggressive military campaign against the drug cartels. These operations were phased-in geographically, and resulted in dramatic and haphazard spikes in violence throughout the country. ${ }^{10}$

While the drug war has been largely concentrated in urban areas, rural areas engaged in

\footnotetext{
${ }^{9}$ The pervasiveness of drug gangs throughout Mexico also manifests itself in the wide-spread presence of other criminal activities such as extortion of citizenry (Díaz-Cayeros et al. 2011).

${ }^{10}$ According to data from the Instituto Nacional de Estadística y Geografía (INEGI), homicide rates increased nearly four-fold in 2008 in municipios within 100 miles of the border.
} 
drug crop cultivation have also witnessed rising violence (Escalante 2009). This has been linked to rival cartels contesting territory in the attempt to control trafficking routes from production areas to the border (Astorga 2007, Ravelo 2008). For example, in the northern state of Sinaloa, La Linea cartel has challenged their rival, the Sinaloa cartel (STRATFOR 2013). Similarly, disputes among cartels in the southern state of Michoacán have been linked to attempts to take over production areas and routes (Maldonado Aranda 2012).

\subsection{Evolution of the Maize Price}

Over the course of the 1990s and 2000s, several major fluctuations in the maize price impacted the income opportunities of maize workers in Mexico. Figure 1 displays the Mexican and international maize prices over 1990-2010. The implementation of the North American Free Trade Agreement (NAFTA) in 1994 initiated liberalization of this sector, expanding import quotas and reducing tariffs. This precipitated a large decline in the price of maize in Mexico: between 1993 and 1994, it dropped by 20\%, the largest one-year decline in our sample period. With the exception of a spike in 1995-1996, prices continuously declined throughout the 1990s. The price jump in 1995-1996, which also appears in the international price, has been attributed to the restriction of Chinese exports and adverse drought conditions in the United States that impacted the maize crop (Stevens 2000). Another weather-related price jump occurred in 2002-2003 in response to a drought episode in the United States. Finally, prices increased sharply in 2005 in what has become known as the International Food Crisis. This has been attributed to a variety of causes, including rising global demand for food and biofuels, as well as weather shocks in important producing countries (Trostle 2008).

\section{Mechanisms}

\subsection{A Snapshot of Maize and Agricultural Workers}

To understand the link between maize price fluctuations and the incentives to produce illicit drugs, it is useful to examine the characteristics of agricultural workers in Mexico at the beginning of our sample period. Table A.1 in the Appendix presents basic demographic statistics for prime-age working men in rural municipios from the 1990 Census. ${ }^{11}$ We focus on three groups: all workers, all agricultural workers, and maize workers. ${ }^{12}$ Maize has historically dominated

\footnotetext{
${ }^{11}$ Rural municipios are defined as those that do not contain any individuals who live in sub-municipio localities of population 100,000 or more in the 1990 Census.

${ }^{12}$ It should be noted that the workers we identify as maize workers are actually classified as "maize and bean workers" in the Census and other surveys administered by INEGI, the official Mexican statistical agency. This unified classification reflects the fact that maize and beans are often intercropped. Workers engaged in the production of one crop are commonly engaged in the production of the other.
} 
the Mexican agricultural sector. About 29\% of agricultural workers (representing $14 \%$ of all workers) were identified as maize workers in 1990. However, this likely understates the number of individuals dependent on maize for a substantial fraction of their monetary income. Fortyone percent of all agricultural workers were not associated with any particular crop, and these unassigned individuals likely grew a variety of crops including maize. ${ }^{13}$

The agricultural sector is characterized by a mix of small-scale family farmers and individuals working for wages on larger farms. Indeed, $48 \%$ of agricultural workers (62\% of maize workers) are classified as "own-account," meaning that they do not have a boss or supervisor. Owners of family farms would fall into this category. Many agricultural workers thus find work as paid employees $(38 \%)$, yet only about $1 \%$ of agricultural workers report directly hiring other workers. About $(7 \%)$ of rural workers work without pay, reflecting the non-trivial presence of family farms. ${ }^{14}$

Workers at nearly every point in the agricultural income distribution can be characterized as poor in comparison to non-agricultural workers in these rural areas. About $27 \%$ of the agricultural workers report earning zero income, consistent with non-trivial rates of subsistence agriculture and unpaid work on family farms. Conditional on earning positive income, the average worker in these municipios earns about 4,500 pesos per month. This is about $\$ 450$ (in 2005 dollars). The income of the average agricultural worker is substantially lower (about 3,150 pesos per month), and the average maize worker earns even less (about 2,500 pesos per month). While there is substantial variation within the set of agricultural workers, it is clear that the vast majority are poor. The 75th percentile of the positive income distribution for agricultural workers (2650) is below the median positive income for non-agricultural workers in these rural areas (3233). In short, maize workers earn relatively little even within the impoverished agricultural sector.

\subsection{Hypotheses Linking Price Changes to Drug Production}

Maize price fluctuations will impact rural households in different ways depending on their production and labor supply choices. First and foremost, such changes directly impact households that initially produce and sell maize. We hypothesize that a fall in the price of maize will tend to increase drug crop cultivation through both substitution and income effects. First, it may provide agricultural households an incentive to substitute out of maize and into the production of other more profitable crops. A price decline should make households poorer, increasing their incentives to spend more time and effort on income-generating activities as the marginal value

\footnotetext{
${ }^{13}$ By contrast, coffee and cacao workers represent the second largest group tied to a specific crop, and account for only $4 \%$ of agricultural workers.

${ }^{14}$ The large fraction of "own account" workers and the fairly high rates of unpaid work are consistent with Mexico's large informal sector, which has been detailed by Levy (2008) and others.
} 
of wealth increases. As we argue in Section A.5 of the Appendix, another income effect may also operate. When the marginal value of wealth increases, households who avoided growing drugs for non-monetary reasons may start growing drugs for the higher absolute monetary payoff. This is consistent with empirical work documenting the impact of moral costs and other non-pecuniary factors on drug supply (Ibáñez and Martinsson 2013). ${ }^{15}$ Furthermore, this channel can explain why drug production may rise with a lower maize price, even holding the relative price of drugs constant. As the price of maize falls, all of these forces should push maize-producing households in the direction of greater drug production.

It is important to note that a fall in the price of maize can cause an increase in the production of drugs even in the absence of a reduction in household production of maize. As described in Steinberg (2004), some small holder maize farmers of the Yucatan peninsula have incorporated illicit drug production into their tradition cropping system (milpa) by intercropping marijuana, maize, and bean plants. Greater drug production can thus be achieved by increasing the total number of plants grown on a fixed plot of land, even if a household does not make a decision to reduce the amount of land devoted to maize.

A change in the price of maize should also affect the wages of those individuals who work as paid employees in the local labor market. A significant fraction of agricultural workers are included in this group. The wage earned by workers on maize farms is clearly tied to the price of maize. Equilibrium in the rural labor market would require that a reduction in the wage of maize laborers ripple through other sectors, reducing the wages of other laborers, agricultural or otherwise. Declining wages in the rural labor market may in turn encourage individuals to increase time spent on other income-generating activities, including drug production.

\section{Data}

\subsection{Measurement of Key Variables}

Our goal is to assess how price shocks impact drug crop cultivation and other drug-trade outcomes. While there are no official statistics tracking illicit crop production across regions of Mexico, we are able to use drug crop eradication as a proxy for cultivation. ${ }^{16}$ Eradication

\footnotetext{
${ }^{15}$ We also acknowledge the possibility of another income effect related to risk aversion. Starting from an initial state in which cultivators grow both maize and drug crops, it could be the case that a fall in the maize price drives farmers closer to subsistence and increases their risk aversion. If drug production is riskier than legal crop production, then a fall in the maize price could reduce drug production. However, anecdotal evidence suggests that rural households in extreme poverty turn to drug production as a way to survive. From one poppy cultivator in Guerrero: "If me and my family didn't grow this crop, we wouldn't have enough to eat or pay for school." (Chandler 2015) We therefore expect a negative relationship between the maize price and drug production, but this is precisely the question our empirical strategy is designed to answer.

${ }^{16}$ As noted by the United Nations Office on Drugs and Crime (UNODC 2011), the Mexican government has not made official estimates of marijuana production available. Even when national-level production estimates exist
} 
activities undertaken by the Mexican military unfold in two stages. First, military surveillance identifies individual fields in each municipio that are planted with marijuana and opium poppy. The military engages in eradication efforts to destroy the illicit crops grown on identified fields. Data from the Mexican military — the Secretariat of National Defense (SEDENA) — record the hectares of marijuana and poppy eradicated in each municipio, over 1990-2010. According to U.S. and Mexican officials, about 75 percent of drug production is eradicated each year (Humphrey 2003), which suggests that eradication is a good proxy for cultivation. As such, we assume that the total area eradicated is informative of the total amount of underlying drug cultivation in a given municipio-year. Figure 2 maps the mean marijuana and poppy eradication across Mexican municipios over our sample period. Drug eradication is concentrated in the western spine of the country, along the western and southern ranges of the Sierra Madres and the adjacent coastal areas. According to the SEDENA data, marijuana eradication increased from approximately 5400 hectares in 1990 to 34,000 in 2003, and decreased to 17,900 in 2010. Poppy eradication started at 5950 hectares in 1990, peaked at 20,200 in 2005, and fell to 15,300 in 2010. We also obtain SEDENA data on drug seizures for the 1990-2010 period. Categories include raw and processed marijuana; opium gum and heroin; as well as cocaine and crystal meth.

To study the relationship between maize price fluctuations and cartel activity across municipios, we use a novel data set constructed by Coscia and Rios (2012). The data track the presence of 10 criminal organizations in each Mexican municipio over 1991-2010. The data set is constructed using a search algorithm that queries archived publications in Google News. The algorithm codes a criminal organization as being present in a municipio if the frequency of hits for a particular municipio-organization pair exceeds a threshold determined by the searchable material available for a given municipio-year. We use the data to generate three measures of cartel presence: an indicator of whether any cartel is present in the municipio (designated "Any cartel"); an indicator for the first year in which any cartel is present in that municipio in our sample ("Cartel entry"), and an indicator for the operation of multiple cartels in that municipio ("Multiple cartels").

Data on drug-related killings come from the Mexican National Security Council, and are available for the 2007-2010 period. Executions are killings attributed to criminal organizations on the basis of tell-tale signs such as the use of beheadings and incinerations, or explicit messages left at the crime scene. Drug-related confrontations measure deaths stemming from fights among

from other sources, analysts have expressed skepticism about their informativeness. Writing about estimates from organizations such as the U.S. Department of State and the UNODC, Kilmer et al. (2010) note that "There are also questions about the validity of the published marijuana production estimates", and conclude that "The bottom line is that we should not place much faith in these supply-side estimates. There are problems and uncertainty in generating supply-side numbers, and the inability to apply consistent, evidence-based methods is a major limitation." (p. 7-8) 
cartels, or between cartels and the army. Cartel attacks refer to deaths stemming from attacks by drug cartels on state security forces. These three variables are aggregated into total drugrelated killings. Figure 3 maps this variable in per capita terms. Clearly this type of violence is concentrated around the border region and areas with drug crops in the northern part of the country.

To examine the impact of maize price shocks, we use a cross-sectional variable of maize suitability. The Food and Agricultural Organization (FAO) of the United Nations provides municipio-level measures of agro-climatically attainable yields for maize under different assumptions about available inputs (FAO 2012b). These indices are based on exogenous factors such as location-specific geography, rainfall, and temperature over the period 1961-1990. Our measure of maize suitability is the average of these FAO indices across different input levels.

We also utilize a soil quality variable from the FAO's Workability dataset. This variable measures land workability constraints that hinder agricultural cultivation. We also develop a measure of municipal ruggedness. The ruggedness in a grid point inside of a municipio is defined as the average difference in elevation between the point and its neighbors, and we take the average across all points in a municipio. We also use municipio-month level measures of rainfall and temperature that originate from the University of Delaware's Center for Climactic Research.

We also use several data sources to account for enforcement. We use data from the Mexican Attorney General's Office (PGR, by its Spanish acronym) to generate a measure of distance to the nearest state security station, defined as either a federal police headquarter, military

garrison, or air-force base in 2000. SEDENA provides municipio-level measures of the number of individuals arrested as a part of government drug war operations over 1991-2010. We control for the log of this variable after adding a one. Finally, municipal-level electoral data from the Center of Research for Development (CIDAC) provides the political affiliation of the mayor, specifically whether he or she is from the left-leaning PRI, conservative PAN or other political party.

\subsection{Sample}

For all outcomes, we restrict our samples to municipios that can be classified as rural. This is important for several reasons. First, we are primarily interested in the impact of maize prices on drug crop cultivation among agricultural producers. This is an inherently rural phenomenon. Also, the relationship between maize prices and illicit activities may be fundamentally different in urban areas where individuals are the consumers of maize rather than producers. In addition, inclusion of urban municipios may lead us to over-estimate the impact on homicides, since dense urban areas with little maize cultivation witnessed a dramatic increase in violence in the late 
2000s as maize prices rose.

To exclude largely urban municipios, we use data from the 1990 Census to calculate the fraction of individuals in each municipio who live in very large urban localities with populations of 100,000 or more. We include in our sample those municipios where no individuals in the 1990 Census lived in such large urban areas. Applying this criterion eliminates 104 municipios, leaving us with a sample of 2,299 municipios. ${ }^{17}$

\section{$5 \quad$ Empirical Strategy}

The impact of maize price fluctuations on drug production in a given area should depend on the extent to which individuals there depend on maize cultivation. Our empirical strategy therefore employs a difference-in-differences approach: we examine whether changes in the price of maize lead to differential effects on illicit activity in municipios more suited to growing maize. Figure 4 maps our FAO maize-suitability measure. ${ }^{18}$ As the figure demonstrates, all states and regions in Mexico contain substantial variation in maize suitability, ensuring that the effects of maize price fluctuations are not driven by any one particular geographic area.

A drawback to directly using the Mexican maize price is that the domestic price may be endogenous to the outcomes of interest. For example, suppose that there is a shock external to maize markets which causes farmers in maize suitable areas to produce more drugs at the expense of maize output. This would cause an increase in the maize price through a supply effect, generating an upward bias (toward zero) on the estimated relationship between maize prices and differential drug eradication. Thus, this form of endogeneity would reduce the magnitude of an estimated negative effect in absolute value terms.

To circumvent this endogeneity concern, we use an instrumental variables strategy that exploits changes in the international price driven by production and exports from the major players in the global maize trade. Note that Mexico accounts for less than 1 percent of global maize exports, and thus movements in the international price are exogenous to its production. ${ }^{19}$ We focus on the production behavior of the four largest maize exporters over our sample period — the U.S., Argentina, France and China.

There is extensive maize trade between the United States and Mexico. Over 99 percent of Mexican maize imports come from the United States. ${ }^{20}$ This largely reflects the reduction of

\footnotetext{
${ }^{17}$ Our panel also does not include 51 municipios that were newly created over the sample period.

${ }^{18}$ This suitability measure is preferable to direct measures of maize production or cultivation, which may endogenously respond to both eradication and contemporaneous maize prices. Furthermore, complete municipiolevel data on land devoted to maize cultivation are only available after 2003.

${ }^{19}$ According to FAO export data, Mexican corn exports accounted for .0012 percent of maize exports over the 1990-2010 period.

${ }^{20}$ This calculation is based on data from the United Nations COMTRADE database, covering the 1990-2010 period (UN COMTRADE 2012).
} 
import tariffs and expansion of import quotas for maize under the NAFTA trade agreement. Given the extent of the maize trade between these two countries, we do not directly use U.S. exports as an instrument, but instead exploit weather conditions in the American Corn Belt as exogenous determinants of U.S. corn production.

As detailed in Appendix Section A.1, we focus on weather shocks affecting all corn-producing counties represented in the USDA Census of Agriculture (2002). Using hourly weather data from the Meteorological Development Laboratory (MDL) of the National Oceanic and Atmospheric Administration, we construct weather indices that average conditions across these counties, weighted by acreage. For each year, we construct USTEMP $P_{t}$, an average day-time temperature index for July, when corn plants flower and are susceptible to severe temperatures. We use both $U S T E M P_{t}$ and its square USTEMPSQ $Q_{t}$, given documented non-linearities in the effects of temperature on yields (Schlenker and Roberts 2009). We also control for an index of the fraction of freezing hours in early April, $U S F R Z_{t}$, along with its square $U S F R Z S Q_{t}$. Freezing temperatures in early April can delay planting and damage early-season corn. Finally, we control for the moisture content of the air by constructing an index of average day-time dew point temperatures in July, $U S D E W_{t}$. We utilize lags of these variables as instruments for the corn price in year $t$, since harvests take place at the end of the calendar year, over October and November. ${ }^{21}$

In contrast to substantial imports from the U.S., Mexico imports trivial quantities of maize from other countries. Given this market segmentation, we directly utilize the export volumes of the three non-U.S. producers as instruments for the national maize price in Mexico. The data for these series come from the FAO (FAO 2012a). Given our difference-in-differences strategy, the validity of the instruments would be violated if these exports were responding to spatially rising drug production in more maize dependent Mexican municipios (which in turn could be associated with falling corn production and a corresponding rise in the price of maize). However, all three export series are negatively correlated with maize prices, which is inconsistent with the idea that export volumes react positively to price spikes brought on by drug production. ${ }^{22}$

Figure 5 plots the relationship between exports, lagged U.S. weather conditions and the international and Mexican maize prices. It shows the negative relationship between exports of the non-U.S. countries and the maize price series. The weather variables affect price through

\footnotetext{
${ }^{21}$ Measures of precipitation could also be used as exogenous weather instruments. We constructed an index of Corn Belt precipitation using monthly data from the University of Delaware's Center for Climatic Research. However, using this index and its square instead of the dew point instrument led to a lower F-test statistic for the joint significance of the weather instruments in explaining the time-series variation in the maize price.

${ }^{22}$ Moreover, the export policies of China and Argentina have been heavily influenced by idiosyncratic political factors. Chinese policies have largely been a function of government export subsidies, and Chinese exports have "fluctuated with little relationship to the country's production, making China's corn trade difficult to predict." (USDA 2013) In Argentina, export licenses are announced irregularly "making it hard for farmers to know how much corn will be released" (Munro 2012) This bolsters the idea that these nations' export behavior are unlikely to respond to Mexican drug production.
} 
multivariate relationships. For example, the dew point should influence the price negatively conditional on the temperature. The price should also be a quadratic function of July temperature. Given these complexities, it is most informative to assess the first stage relationships visually by examining the sixth panel of this figure, which shows the predicted price based on our instruments.

Appendix Table A.2 also presents simple time series regressions of these relationships. These corroborate that the time-varying components of our instruments are important determinants of the maize price, even after we control for the U.S.-Mexico real exchange rate and a linear time trend. The instruments are jointly significant at the 1 percent level, with a F test-statistic of 63.57. ${ }^{23}$ This underscores the strength of the time series relationships underlying our empirical strategy.

Let $Y_{i t}$ refer to the value of dependent variable $Y$ in municipio $i$ during year $t$. Our basic second-stage specification is given by:

$$
Y_{i t}=\alpha_{2 i}+\tau_{2 t}+\mu_{2 i} t+\left(M A I Z \widehat{E_{i} \times} P R I C E_{t}\right) \delta+\mathbf{X}_{i t}^{\prime} \phi+\varepsilon_{i t}
$$

Here the $\alpha_{2 i}$ are second-stage municipio fixed effects that control for time-invariant characteristics of Mexican municipios; $\tau_{2 t}$ are second-stage year fixed effects that account for common shocks in a given year; the $\mu_{2 i} t$ terms represent second-stage municipio-specific time trends; $M A I Z E_{i}$ is the average agro-climatically attainable yield for maize per hectare in municipio $i$; $P R I C E_{t}$ is the natural $\log$ of the national maize price in year $t$; and the coefficient $\delta$ is our main parameter of interest measuring the differential effect of maize prices on the outcome in municipios with higher maize suitability. ${ }^{24} \mathbf{X}_{i t}$ is a vector of additional controls which varies across specifications.

The first stage equation explaining $M A I Z E_{i} \times P R I C E_{t}$ is given by:

$$
\begin{aligned}
M A I Z E_{i} \times P R I C E_{t}= & \alpha_{1 i}+\tau_{1 t}+\mu_{1 i} t+\left(M A I Z E_{i} \times C H N_{t}\right) \gamma+\left(M A I Z E_{i} \times A R G_{t}\right) \lambda \\
& +\left(M A I Z E_{i} \times F R A_{t}\right) \theta+\left(M A I Z E_{i} \times U S D E W_{t-1}\right) \psi \\
& +\left(M A I Z E_{i} \times U S T E M P S Q_{t-1}\right) \zeta+\left(M A I Z E_{i} \times U S T E M P_{t-1}\right) \beta \\
& +\left(M A I Z E_{i} \times U S F R Z_{t-1}\right) \sigma+\left(M A I Z E_{i} \times U S F R Z S Q_{t-1}\right) \eta \\
& +\mathbf{X}_{i t}^{\prime} \rho+\omega_{i t}
\end{aligned}
$$

\footnotetext{
${ }^{23}$ Each weather instrument affects the maize price in the hypothesized direction. The $U S F R Z_{t}$ variable exhibits a non-linear relationship with the corn price, with exceptionally cold springtime weather being detrimental to corn yields. The $U S D E W_{t}$ variable is negatively associated with the price, reflecting the fact that low-moisture conditions hurt corn yields. Also, USTEMP $P_{t}$ is non-monotonically related to the corn price, consistent with the idea that yields first rise with warmer weather and then fall with extreme heat.

${ }^{24}$ Note that the base terms of the interaction do not appear separately in Equation (1) since $P R I C E_{t}$ is absorbed by year fixed effects while $M A I Z E_{i}$ is absorbed by municipio fixed effects.
} 
Here $\alpha_{1 i}$ and $\tau_{1 t}$ represent first-stage municipio and year fixed effects, respectively. The $\mu_{1 i} t$ terms are first-stage municipio-specific time trends. $C H N_{t}, A R G_{t}$ and $F R A_{t}$ represent the log of Chinese, Argentine and French maize exports in year $t$. As discussed above, the U.S. weather instruments enter with a lag.

Since $M A I Z E_{i}$ is the attainable yield per hectare, we scale marijuana and poppy eradication by municipal area, measuring these outcomes per 10,000 hectares. Killings are measured as a rate per 10,000 population. We take the log of all dependent variables after adding a one. This ensures that municipio-year observations with zero eradication or homicide levels are included in our specifications. Unless otherwise noted, all parameters are estimated via 2SLS, and our standard errors are clustered at the municipio level.

Figure 1 shows that the price of maize trended downward over much of our sample period. If eradication also trended upward differentially in maize suitable municipios, for some reason besides this price fall, this could confound our estimates. We include municipio-specific trends in our preferred specification to control for divergent trends based on maize suitability, and other cross-sectional characteristics correlated with this suitability. For example, if maize suitability is correlated with proximity to police stations, and eradication trends diverged among places that are further vs. closer from these stations, municipio-specific trends would control for this potential bias. ${ }^{25}$

Our preferred specifications control for two other factors that govern agricultural production. If places suited to growing maize generally have better soil, this raises the possibility that estimated increases in drug production will reflect land quality differences, rather than the effect of maize per se. We therefore control flexibly for the effect of soil quality by introducing interactions of year effects with our land workability measure. We also control for time-varying rainfall and temperature conditions in Mexican municipios over June and July, as well as temperature conditions during the early maize planting period in April and May. ${ }^{26}$ Table 1 presents the descriptive statistics of the key variables in our analysis. ${ }^{27}$

\footnotetext{
${ }^{25}$ Additional specifications presented in the appendix do not include municipio-specific time trends but instead control for trends based on various economic, geographic, and policy characteristics of municipios. These controls are outlined in Section A.1 of the Appendix.

${ }^{26}$ We opt for these weather controls since more fine-grained, hourly measures such as number of freeze days in a particular month are not available with sufficient coverage for Mexico, at the level of the municipio. However, in Appendix Table A.4, we show the robustness of our results to different types of weather controls.

${ }^{27}$ Note that we present descriptive statistics for the sample of 2,296 municipios and 48,216 municipio-year observations. This is our baseline sample featuring non-missing data for our primary controls. Some regressions may feature different numbers of municipios or municipio-year observations depending on the availability of data for the included controls.
} 


\section{Main Results}

\subsection{Maize Prices and Drug Production}

In this section we examine the relationship between maize prices and drug production. Our main estimation strategy tests for differential impacts of price changes on municipios of varying maize suitability. We begin by presenting visual evidence of these difference-in-differences effects. Figure 6 graphs the national maize price alongside the difference in log eradication and seizure outcomes between municipios with above and below mean maize suitability. For all four outcomes, the differences increased as the price fell sharply over 1990-2005. The differences also decreased after 2005 when the maize price started rising. This figure is merely suggestive as it is devoid of any controls, and divides the suitability measure discretely around the mean cutoff. Nonetheless, the patterns strongly suggest that declines in the maize price correspond to differential increases in drug-related outcomes among more maize dependent municipios. ${ }^{28}$

Next, we build on this visual evidence by presenting regression estimates of equation (1). Table 2 focuses on our main drug production outcomes, which proxy drug crop cultivation with eradication. Columns (1)-(2) show the OLS estimates and Columns (3)-(4) show the IV estimates with limited controls: municipio and year fixed effects, log population, and maize suitability interacted with the real exchange rate. We progressively add controls in the remainder of the table. Columns (5)-(6) incorporate the weather and land quality interactions. Columns (7)-(8) instead include linear time trends for each municipio. This is a stringent test as it includes a separate trend for each of the 2296 municipios in the sample.

In Appendix Table A.3, we show that our results look similar if we replace municipio-specific trends with trends by specific economic and enforcement factors including distance to border, highway presence, proximity to a security station, rurality and beginning period agricultural income. ${ }^{29}$ The estimates are also robust to alternate weather controls in Mexico-i.e., squared terms of our baseline rainfall and temperature variables or separate linear controls for rainfall and temperature in each month of the year.

The significant negative coefficients across all specifications in Table 2 and A.3 indicate that a rise in the price of maize leads to a differential fall in drug crop cultivation among municipios more suited to growing maize. The consistency of the estimates with and without trend controls demonstrates that our results are not driven by divergent eradication trends which coincide with the maize price fall over the 1990s. Also, the data suggest that the price of maize is negatively associated with aggregate production. In Appendix Table A.4, we present specifications in which the maize price is not interacted with cross-sectional maize suitability, and our estimates

\footnotetext{
${ }^{28}$ The difference in opium seizures is relatively low over this period since the level of opium seizures was low nation-wide at this time.

${ }^{29}$ See Appendix section 1 for a description of these variables.
} 
indicate a negative relationship with both marijuana and poppy eradication. ${ }^{30}$

The IV estimates are somewhat larger in magnitude than the OLS estimates, which is consistent with reverse causality from supply effects biasing the least squares estimates toward zero. The estimates in columns (7)-(8), which include the weather and land quality controls, as well as municipio-specific trends, serve as our baseline specification. The coefficients of -0.033 and -0.013 for marijuana and poppy eradication imply economically meaningful effects. The price of maize fell by 59 percent between 1990 and 2005 (decline of 0.88 log points). To examine the effect of this price fall, we consider a municipio at the 10th percentile of the maize suitability distribution $(M A I Z E=4.50)$ and another at the 90th percentile $(M A I Z E=8.63)$. For marijuana, moving from the 10th to the 90th percentile of this distribution implies that a 59 percent price fall would induce 12 percent more eradication. The equivalent calculation for poppy implies 4.7 percent more eradication. In the remainder of the paper, we refer to municipalities at the 90 th vs. 10th percentile of the suitability distribution as those with a high vs. low maize suitability.

The smaller effect on the poppy outcome may reflect the more limited reach of Mexico's heroin trade vis-à-vis marijuana. The scale of heroin trafficking escalated relatively late in the sample period, after 1998. Poppy cultivation also faces a sharper set of agro-climatic constraints and is therefore grown in more specific, often mountainous areas like the Sierra Madres (See Figure 2). Consistent with this interpretation, we show below that the poppy effects are larger in rugged terrain and areas better suited to growing these drug crops.

Table 3 presents the first stage associated with our baseline specification (Columns 7-8 of Table 2). This demonstrates the strong relationship between our instruments and the endogenous variable. The rk Wald F statistic is 2.6e+06, which exceeds the relevant Stock Yogo critical value. Since both sides of the first-stage equation are products of time-invariant maize suitability and the time-series variables (maize price, U.S. weather conditions, and exports of other major maize producers), this raises the possibility that the strength of the first stage is driven solely by the cross-sectional suitability. However, as discussed in the Empirical Strategy section, the time-series instruments stand on their own as strong predictors of the Mexican maize price (see Appendix Table A.2, which shows time-series regressions of the maize price and our instruments).

The planting decisions of farmers represent the first steps in the narco-trafficking chain.

\footnotetext{
${ }^{30}$ These significant relationships between the price of maize and these drug production outcomes suggest that there was net rise in drug production when the price of maize fell during the 1990s. For example, among our sample municipios, total marijuana eradication started at 5257 hectares in 1990 when the price was high, climbed to 23,360 hectares in 2005 when the price was at its lowest point, and ended at 17405 hectares in 2010 after the price had risen again. Similarly, poppy eradication started at 1581 hectares, rose to 17,565 hectares in 2005, and ended at 15,184 in 2010. Thus while our difference-in-difference effects may stem, in part, from lower drug production in some municipios and higher drug production in others, this aggregate rise in eradication helps assuage concerns that the effects are driven entirety by this type of substitution.
} 
After drug crops are grown, they are harvested, packaged, and processed. Given our results on eradication, we next explore whether there are differences in post-cultivation outputs. We utilize data on drug seizures, which offer a separate measurement of drug production in a municipio. These data are categorized into three groups: outputs that emerge directly from harvesting marijuana and opium poppies - i.e., raw marijuana and opium gum; outputs that emerge from further refining these raw outputs - i.e., processed marijuana and manufactured heroin; and other outputs that are unrelated to these two drug crops - i.e., seizures of cocaine and crystal meth.

In Table 4, we find substantial negative effects on the seizures of raw marijuana. The coefficient in Column (1) of Panel A suggests that a 59 percent maize price fall would result in 10.2 percent more raw marijuana seizures in municipios with a high vs. low maize suitability. This is in direct contrast to the effects on processed marijuana. In the sample including all municipios, we observe a significant positive coefficient for processed marijuana, but this is an artifact of higher drug seizures in municipios near the U.S.-Mexico border. When the 107 municipios near the border are taken out of the sample in Panel B of Table 4, we see that there are no significant effects on processed marijuana outputs. Although this border phenomenon could reflect confounding changes in enforcement, it is also consistent with our overall account. Municipios near the border have low values of maize suitability (See Figure 4), ${ }^{31}$ but seizures of processed marijuana are concentrated there, since trafficking routes necessarily come through these areas. When a fall in maize prices differentially increases production in highly maize suitable places where farmers grow drug crops, it may also differentially increase processed marijuana seizures in low maize suitable border municipios where that drug output is trafficked. ${ }^{32}$

We also observe negative coefficients for seizures of opium gum, and insignificant positive effects for seizures of processed heroin. However, the negative opium effects are imprecisely estimated and small compared to the other statistically significant effects we estimate. Finally, we find no evidence that maize price changes affect the seizures of other processed drugs (the $\log$ sum of cocaine and meth seizures) in Table $4 .{ }^{33}$

\footnotetext{
${ }^{31}$ The entire sample has an average maize suitability of 6.64. Municipios near the border have an average maize suitability of 4.62 , which is at the 12 th percentile of the maize suitability distribution.

${ }^{32}$ Trafficking routes converge at municipios that lie on the border, but span beyond the immediate vicinity of these crossing-points. If our interpretation is correct, then the effect on processed marijuana seizures should diminish as we analyze areas that progressively eliminate municipios close to the border. Consistent with this account, Table A.5 shows that the effects on processed marijuana seizures falls when we remove the municipios that are immediately contiguous to the border, and falls further still when we remove the municipios that are within 100 miles of the border. See Appendix Section A.3 for further discussion.

33 The border effect is likely to be particularly strong for seizures of processed marijuana (versus other processed drugs) because these are the most common types of drugs trafficked along the U.S.-Mexico border. For example, The Center for Investigative Reporting analyzed nearly 130,000 drug seizures that took place at the border over 2005-2011, and found that almost 89 percent of them constituted marijuana seizures. Cocaine and meth together constituted less than 10 percent, while heroin constituted approximately 1 percent. For their
} 
The negative estimates for raw versus processed components accord with our expectation that the maize price affects the output decisions of farmers, but does not necessarily affect cartel incentives to process drugs in particular areas. These results suggest that home-grown drug crops are produced in rural locations, even if processing takes place elsewhere. In the remaining tables of the paper, we focus on the seizures of raw marijuana and opium gum - the relevant cultivation-related drug outputs. However, in Appendix Tables A.5-A.6, we also verify that there are null effects on other drug seizures and processed marijuana seizures away from the border for all subsequent specifications shown in the main tables. In addition, Table A.7 verifies that dropping the municipios near the border doesn't alter estimated effects on other outcomes examined in our analysis.

The strength of the relationship between maize prices and drug cultivation should theoretically depend on a number of mediating factors. In Table 5, we present evidence of heterogeneous effects based on several relevant municipio-level characteristics. First, the effect of a maize price shock on drug production should depend on the ease with which farmers can grow other legal crops. To test this idea, we use data from the 1990 Census to calculate a Herfindahl Index of employment in non-corn cultivation for each municipality. ${ }^{34}$ We view locations with low concentration levels as having high levels of other-crop diversity, and thus, supporting a wider range of agricultural alternatives to maize. Consistent with this interpretation, less concentrated locations are associated with more agricultural employment. ${ }^{35}$

Panel A of Table 5 presents the eradication results for municipios with above and below median other-crop concentration. In line with expectations, we estimate larger effects across both outcomes in locations with higher concentration levels. For example, the effect for marijuana eradication is -0.030 in the below median group (in Column 1) and -0.040 in the above median group (in Column 3). This implies a more than 30 percent larger effect size in above median locations. ${ }^{36}$ Similarly, the effect for poppy eradication is -0.021 in the above median group (in

visual representation, see: http://static.apps.cironline.org/border-seizures/

${ }^{34}$ We take the fraction of non-corn cultivators associated with each of the nine cultivator categories listed in the Census, and sum the squares of these fractions to obtain this index. The nine cultivator categories are: cereals, cotton / agave, vegetables, coffee / cacao, tobacco, fruit, flowers, other crops, none-specified. We calculate the fractions for all economically active men who list their occupation as one of these cultivation categories.

${ }^{35}$ Simple bivariate regressions show a significant negative relationship between the concentration index and the share of agricultural workers in a municipality, as well as the share of non-corn cultivators in a municipality. Also, when we divide our sample into groups based on the median of the index, we observe that on average, $34 \%$ of working males were employed as non-corn cultivators in municipios with an above median concentration index, while the corresponding average is $38 \%$ in below median municipios. In addition, on average, $62 \%$ of working males were agricultural workers in the above median locations, while $64 \%$ worked in agriculture in the below median locations. This provides evidence against the idea that low concentration locations are those in which individuals grow many different crops, but none particularly well, giving rise to little aggregate agricultural employment.

${ }^{36}$ Specifically, a $59 \%$ price fall would induce 10.9 percent more eradication in a municipio at the 90 th vs. 10th percentile of the maize suitability distribution among below median locations; this difference rises to 14.5 
Column 4), while it is -0.008 in the below median group (Column 2). The effect size is more than two-fold larger in the above median locations. ${ }^{37}$

We also expect the effect of a price change on marijuana or opium poppy cultivation to be larger in those areas that are better suited to growing these illicit crops. In the absence of pre-existing data on drug crop suitability, we use the average values of marijuana and poppy eradication in a municipio over the period 1990-1993 as a simple measure of a municipio's suitability for growing either of these crops. Panels B-C of Table 5 show that the estimated effects are larger in areas with above median drug suitability. ${ }^{38}$ For marijuana eradication, the coefficient is -0.080 in the above median group (Panel B-Column 3). This implies that a $59 \%$ price fall boosts eradication by 29.1 percentage points more in high vs. low maize suitable places. For poppy eradication, the coefficient is -0.071 in the above-median (Panel C-Column 4). This suggests a 25.8 percentage point differential increase in eradication among high vs. low maize suitable municipios.

These panels also reveal that there are important cross-crop suitability effects. There are larger differential price effects on both marijuana and poppy outcomes in municipios with above median marijuana suitability, and above median poppy suitability. These cross-crop effects are consistent with the important role that mountainous areas play in drug crop production (Humphrey 2003). High elevation is required for poppy cultivation. Mountainous areas may also be well suited for marijuana production both because of the existing drug-trade infrastructure and because rugged terrain helps farmers conceal illegal activity. Panel D of Table 5 shows that when we split the sample based on ruggedness, the effects are larger in more rugged areas. ${ }^{39}$

Finally, we expect the effects on drug production to vary based on proximity to military bases and police headquarters. The likelihood of getting detected is lower among municipios located farther from security stations. In Panel E, when we divide municipios based on median distance to these stations, we observe larger effects on both types of eradication outcomes among municipios that are farther away. These effects bolster our interpretation that changes in drug eradication reflect changes in drug cultivation. If changes in eradication were primarily driven by changes in enforcement targeting, we would expect to observe precisely the opposite effects - eradication responses to maize price shocks should then have been larger closer to security stations, where the costs of detecting and eradicating drug crops are lower. Overall,

percent for two such municipios among above median locations.

${ }^{37}$ For all panels of Table 5 , we verify that the mean and standard deviation of the maize suitability variable are similar for the municipios in the below-median and above-median groups. Thus, smaller effects in the below median grouping cannot be attributed to limited variation in the area's ability to support maize.

${ }^{38}$ Note that more than $50 \%$ of municipios are observed with zero marijuana and poppy eradication over the period 1990-1993. Thus, the below median group contains more than half of the observations.

${ }^{39}$ Ruggedness in a particular geographic point inside of a municipio is defined as the average difference in elevation between a grid point and its neighbors. The ruggedness measure is the average ruggedness for all points in a municipio. 
these results provide assurance that marijuana and poppy eradication serve as good proxies of drug crop cultivation, since we estimate larger effects among five municipal groups where we theoretically expect greater drug production responses to an agricultural price shock.

In the Appendix Table A.8, we present the analogous heterogeneous effects on raw marijuana and opium gum seizures. We estimate larger coefficients on raw marijuana seizures in the above median sample for all five groups. These effects are precisely estimated for the splits based on other crop concentration and distance to police station. The pattern is less discernible for opium gum seizures, and all the coefficients for this outcome are small in magnitude. This is unsurprising given that the baseline effect for this outcome is also small and imprecisely estimated (Table 4).

We posit that the drug production effects shown in Tables 2, 4 and 5 reflect the adverse impacts of maize price shocks on household economic conditions. As described in our mechanisms section, when the price of maize falls, households in maize suitable areas are likely to experience a fall in their income opportunities. In the Appendix Section A.2, we present evidence consistent with this hypothesis.

We use 11 rounds of the Encuesta Nacional de Ingresos y Gastos en los Hogares (ENIGH) a nationally representative survey of Mexican households - to examine effects on various labor market outcomes. ${ }^{40}$ Given the short time series available for any given municipio, we are unable to include trends by municipio or maize suitability. ${ }^{41}$ However, we can control for trends based on other economic and enforcement characteristics, which are detailed in the Appendix. We find these results to be informative, as we show that our main drug production estimates look very similar if the municipio-specific trends are replaced by this alternate control set (Columns 1-2 of Table A.3).

As shown in Appendix Table A.10, maize price shocks are associated with adverse effects on a number of employment and income indicators. Negative maize price shocks differentially reduce hourly wages in more maize suitable areas. These wage effects are large for maize and bean cultivators, and both small and statistically insignificant for cultivators of other crops. Negative price shocks also increase the differential propensity to engage in subsistence employment. These results are consistent with previous work indicating that subsistence farming increased in Mexico after NAFTA's implementation (Janvry et al. 1995 and Yunez-Naude and SerranoCote 2010). More generally, they suggest that our difference-in-difference effects reflect changes in income opportunities related to maize workers.

\footnotetext{
${ }^{40}$ Descriptive Statistics of these variables are shown in Appendix Table A.9.

${ }^{41}$ Not every municipio is sampled every year: $57 \%$ of them appear for three or fewer years.
} 


\subsection{Cartel Activity and Violence}

The results in the previous subsection provide evidence that declining maize prices stimulate increased drug production. Such activity is inextricably tied to the operation of cartels which play a key role enabling the transport and sale of drugs in international markets. Cartels either directly purchase drugs produced by small holders or hire laborers to cultivate drugs on lands that they control (Humphrey 2003). In either case, we posit that Mexican cartels act as monopsonies in local drug crop markets. These cartels, like other criminal organizations, are highly territorial and use violence to defend claims to particular bases of operation (Kan 2012, Knight 2012). If a cartel controls a swath of territory from which it sources illegal drug crops, we assume that it maintains complete market power in dictating the price paid to small holder producers or the wage paid to hired cultivators. This is consistent with accounts of marijuana farming in the mountainous regions of Sinaloa (Río Doce 2012).

Suppose that cartels purchase drug output from small holders at a chosen farm gate price, and then sell these drug crops abroad at the prevailing international market price. The farm gate price that a cartel offers local farmers will be determined both by the international price and by the supply curve of local farmers. When the value of alternate income generating activities falls, as is the case when the maize price declines, cartels can exploit their monopsony power, reduce the farm gate price, and extract greater surplus from their suppliers. As such, the value of controlling a particular territory should increase as the outside options of local farmers deteriorate.

This account implies a set of predictions related to the expansion of cartel activity and patterns of inter-cartel violence. In addition to solving a local monopsonist's problem, cartels must also decide where to base their operations, whether or not to expand into other territories, and whether or not to actively contest the hegemony of an incumbent cartel. If falling maize prices make maize-dependent areas more valuable, we should expect cartels to expand into these areas, increasing the likelihood of violent confrontations between multiple cartels.

Table 6 presents our findings on the activity of drug cartels. The first three columns examine the variables derived from the Coscia and Rios (2012) data. These results suggest substantial effects on cartel presence. The coefficient in Column (1) tells us that a $59 \%$ price fall boosts the likelihood of any cartel being present by about 0.10 in a high vs. low maize suitable municipio. The mean of this outcome is small (0.058), so this implies a large effect in percent terms (172 percent of the mean), but this is of course a consequence of starting from a low base. Analogously, the coefficient estimate in Column (2) indicates that the same price decline would increase the probability of multiple-cartel operation differentially by 0.07 , relative to a base mean of 0.03. Finally, Column (3) shows that first-time cartel entry into a municipio 
increases differentially by 0.06 , over a base mean of $0.02 .{ }^{42}$

In the remaining columns of Table 6, we examine killings related to the drug war. Data on these outcomes are only available for the 2007-2010 period. Since this spans four years, we are not able use our eight instruments separately for analyzing these outcomes. We instead implement a 2SLS strategy by first generating an instrument for the maize price which essentially combines the exogenous variation from all of the instruments. In this pre-first-stage, we regress the national maize price on our eight instruments using the full sample period (over 1990-2010). Using information from all 21 years of data allows us to more efficiently predict the maize price, conditional on the instruments, relative to using only four years of data. We then use the predicted price for 2007-2010 as a generated price instrument in a standard 2SLS analysis - i.e., we instrument the endogenous interaction of maize suitability and price with the interaction of maize suitability and this generated price. ${ }^{43}$ We are able to include all control variables in our baseline specification, with the exception of the annual exchange rate control, as this constitutes yet another time series variable interacted with $M A I Z E_{i}$. However, columns (3)-(4) of Appendix Table A.3 show that removing this variable makes virtually no difference to the magnitude or statistical significance of the coefficients for our main drug production outcomes.

Total drug war-related killings are composed primarily of cartel executions (85\%), but also include deaths from cartel confrontations with each another and state security forces $(13 \%)$ and cartel attacks on state security forces $(2 \%)$. We begin by presenting effects on total killings and then examine the sub-outcomes in each of the other remaining columns. The estimate in Column (4) suggests that reductions in the price of maize increase total drug war killings. It implies that the 8 percent increase in maize prices over 2007-2008 led to 11 percent fewer total killings in high vs. low maize suitable municipios. The remaining columns show that the increase in total killings stems primarily from increased executions. This effect suggests a rise in inter-cartel conflicts. Executions are an important component ongoing cartel wars since they send clear signals to cartel members - either by targeting members of rival gangs, or by targeting members of own gangs for snitching or other forms of betrayal. In contrast, attacks exclusively target state security forces, while confrontations may also involve the state. ${ }^{44}$

\footnotetext{
${ }^{42}$ One may be concerned that the cartel data only provide another measurement of eradication, since they are based on news archives and the media may cover the drug-war more in areas that experience visible events such as eradication. To account for this possibility, we control for both marijuana and opium poppy eradication in Table A.11. The cartel effects remain the same in size and significance, which suggests that they measure an additional aspect of the drug trade beyond drug eradication.

${ }^{43}$ As Wooldridge (2010, p. 125) indicates, no additional steps are required to adjust the standard errors with generated instruments, if 2SLS is used for inference.

${ }^{44}$ While the data do not break down confrontations into sub-categories, a large fraction are likely to involve state security forces. Confrontations with the military are always observable to the office of the presidency, from where these data originate. In contrast, only a subset of confrontations among rival cartels are readily observable by state officials.
} 
While these outcomes represent a notable consequence of maize price shocks on cartel violence, we interpret them with greater caution as they are estimated on the basis of a short time series. In remaining tables, we focus on the presence of drug cartels as our as our primary measure of cartel activity. However, in Appendix Table A.12, we also demonstrate the robustness of these results on drug war killings to all additional specifications that follow.

\section{Threats to Identification}

Next, we address possible threats to our identification strategy, which cover three themes. First, eradication may be a problematic measure of drug crop cultivation if changes in eradication reflect endogenous policy decisions rather than changes in output. Second, enforcement trends may confound our estimates if they are correlated with changes in the price of maize. Third, evolving conditions in the rural sector, including those related to agricultural policy, may generate bias if they co-evolve with maize prices.

\subsection{Enforcement and Eradication as a Measure of Production}

We have assumed that the number of hectares of a particular drug crop eradicated serves as a good measure of the overall quantity of drug production. In fact, studies have suggested that a very high percentage of drug crops are actually eradicated in a given year. ${ }^{45}$ For eradication to serve as a good proxy, it should be the case that as drug production rises in a location, government eradication also rises proportionately. As such, scenarios in which the government anticipates that more drugs will be grown in maize suitable areas after an adverse price shock are not inconsistent with our interpretation, and would not, in and of themselves, bias our estimates. In fact, our empirical strategy requires that the government is aware of local production changes and responds accordingly. However, if the eradication response is more than proportionate, then this tendency could generate upward bias. More broadly, our interpretation of the results will be threatened if the maize price fluctuations cause officials to alter the differential volume of eradication across municipios for reasons other than production changes.

To address these concerns, in Table 7, we control for time-varying factors that would either produce or reflect disproportionate local enforcement responses. One such factor is the local political dynamic. It could be the case that declining maize prices cause differential shifts in political attitudes in maize suitable municipios which are translated into local policy responses. Eradication may then increase more than proportionally to drug production if the party elected to office favors stronger enforcement efforts. Consistent with this, Dell (forthcoming) provides

\footnotetext{
${ }^{45}$ As previously mentioned, Humphrey (2003) suggests that about $75 \%$ of marijuana production is eradicated.
} 
evidence that the local political party affiliation of a municipio's mayor exerts substantial impacts on the dynamics of the drug war. To control for this effect, we include time-varying binary regressors indicating whether or not a municipio's mayor was a member of PAN, (the political party associated with more aggressive anti drug-trafficking policies), the PRD, or another party.

We also control for the (log) number of individuals arrested in drug war operations. Basic summary statistics suggest that this variable is an excellent proxy for capturing enforcement dynamics. As shown in Figure A.1, the average number of detentions increased sharply after the 2005 start of anti-cartel military operations. At the same time, this variable is almost surely an over-control, since local law enforcement efforts will respond to increased drug trade activity. Table 7 indicates that all of our results remain significant at conventional levels even with these enforcement controls. Despite the smaller sample available for this specification, ${ }^{46}$ the magnitude of the coefficients do not change in a systematic manner relative to baseline specifications. The effect on poppy eradication is smaller, while the effect on raw marijuana seizures is larger.

An alternate critique posits that eradication could differentially change in maize dependent municipios as the maize price falls if local budgetary resources endogenously adjust. However, the most likely scenario is that as the price falls, maize dependent municipios would see greater strain placed on local budgets, decreasing resources used in support of federal eradication. We would therefore expect endogenous budgetary resources to attenuate estimated impacts of maize prices. Our specifications, which do not control for budgetary resources, likely represent a lower bound on the true effects.

Although we are not able to observe local enforcement budgets, or allocations devoted specifically to eradication, we are able to observe aggregate military expenditures at the national level, which include resources for drug eradication. In addition, we can measure the total number of personnel in the armed forces, which is relevant for the drug war because soldiers both partake in anti-cartel campaigns and conduct manual eradication of illicit crops. Finally, we can track the amount of military aid provided to Mexico by the United States. Much of this assistance has been provided for counternarcotics purposes, including equipment that has facilitated eradication missions (GAO 1998). Figure A.1 plots the time series of these three variables reflecting national enforcement efforts, alongside the predicted maize price. The figure shows no systematic relationships between these variables and our price variation for most of the sample period. The exception is the period after 2005. In that year, the price of maize pivots upward as a result of the World Food Crisis. Government military expenditures and armed personnel also pivot upward as a results of the Calderón administration's anti-drug military campaigns. This denoted a marked shift in the Mexican drug war strategy - the administration

\footnotetext{
${ }^{46}$ The samples for these specifications are smaller than in the baseline specifications because of missing data on mayoral party affiliation, and because the drug war detentions variable is unavailable for 1990 .
} 
prioritized attacking cartels in urban areas, which may have lowered resources available for eradication in rural areas, including more maize suitable municipios. This suggests that it may be important to account for the coincidence of these two trends. We do so by controlling for maize suitability interacted with these three time series in Panel A of Appendix Table A.13. ${ }^{47}$ In Panel B of this table, we additionally incorporate our local enforcement controls. In both specifications, we estimate larger coefficients on both eradication outcomes relative to baseline effects (in Table 2). The coefficients also retain their statistical significance for all outcomes, with the exception of raw marijuana seizures. This likely reflects loss of precision from additional collinear controls, since this coefficient also increases in magnitude relative to baseline estimates (in Table 4). Overall, these results suggest that enforcement dynamics do not lead us to over-estimate the impact of maize price shocks on drug production.

In addition, we investigate the validity of using eradication as an outcome by developing and calibrating a model of endogenous drug eradication in Appendix section A.4. In the model, the government decides each year how to optimally allocate eradication resources across municipios of heterogeneous maize and drug suitability. The government observes drug production and decides how much to eradicate in each municipio. We calibrate the model to match important features of our data. Using the calibrated model, we are able to perform Monte Carlo simulations that assess how our basic difference-in-differences estimator would perform using endogenous eradication data versus the underlying latent drug data. The results indicate that we would obtain estimates of similar magnitudes using either source of data, and if anything, they would be larger using output data.

Our interpretation of the results will also be threatened if the process of eradication alters the incentives to produce drugs in the future — either by destroying household resources, or by changing expectations about the future risks of drug production. This concern would be greatest for perennial plants like coca (used to manufacture cocaine). In contrast, marijuana and poppy are annual crops that need to be replanted each year. For these crops, eradication in a particular year does not reduce a household's ability to grow drugs in the future. Generally, it is reasonable to presume that the risk of eradication is understood by growers. However, we can also assess the nature of serial correlation in the eradication process by incorporating lags of the dependent variables. These are of course, endogenous controls. As such, we take these specifications to be suggestive, and most informative for gauging the type of serial correlation that arises. Appendix Table A.16 presents these results for different time periods and control sets. The coefficients on the lag eradication variables are always positive and significant. This is inconsistent with stories in which heavy eradication in one period leads to a substantial reduction in eradication in the next period. In the baseline specification our main difference-

\footnotetext{
${ }^{47}$ We are not able to estimate impacts on drug war killings with these additional time-varying controls since we have limited time series variation with just four years of data, over 2007-2010.
} 
in-differences estimate becomes attenuated and insignificant for the poppy outcome. ${ }^{48}$ This appears to be related to the enforcement policy change in 2005, which could have altered the autoregressive structure of eradication, for example, by altering perceived eradication risk across this period. If we account for this change by incorporating a control for the post-2005 period or dropping these latter years, the coefficient retains its significance (see Appendix section A.3 for further discussion). Overall, these results suggest that there appears to be quite a bit of persistence in eradication. ${ }^{49}$

In Appendix Table A.17, we also account for concerns that other changes (such as enforcement policy) induced differential trends in eradication through various alternate strategies. Each of these specifications includes alternative types of trend controls in lieu of municipiospecific trends in the baseline specification. First, we account for non-linear trends. Since maize prices fell prior to 2005 and rose thereafter, our results could be spurious if some other factor caused drug production to trend upward differentially in more maize-suitable before 2005, and then caused it to trend downward differentially in these areas after 2005. It is difficult to imagine a factor that would cause such a specific reversal in underlying trends. (For example, military resources devoted to enforcement were rising after 2005, but they were not decreasing beforehand-see Appendix Figure A.1). Adding additional terms for non-linear trends by maize suitability is almost surely an over-control, as these terms will soak up two of the most important sources of price variation in our sample - the fall prior to 2005 and the rise thereafter. Nonetheless, in Panel A of Table A.17, we add three such trend controls: an annual trend interacted with maize suitability, an indicator for the five years after 2005 interacted with maize suitability, and an annual trend interacted with both maize suitability and an indicator for the five years after 2005. The coefficient estimates remain statistically significant for all outcomes, with the exception of raw marijuana seizures, although this change arises from inflated standard errors, as the point estimate remains economically substantial.

In Panel B, we eliminate the post-2005 period from the sample. This is an alternate way of examining whether the 2005 military policy change, and differing trends in maize suitable municipios after 2005 influence the estimated effects. However, we observe significant impacts

\footnotetext{
${ }^{48}$ Note that the magnitudes of the MAIZExPRICE effects in these specifications should not be directly compared to those in Table 2 because of persistence in these models.

${ }^{49}$ This discussion also raises the question of why farmers continue to grow drug crops when they face risk associated with drug crop cultivation, as reflected in eradication and other factors. Qualitative accounts from the Yucatan peninsula suggest that drug lords take some steps to minimize these risks. For example, they provide seed and fertilizer and a guaranteed market for the harvested crop (Steinberg 2004, p. 170). In addition, many rural workers are hired to work as laborers on farms operated by cartels (Humphrey 2003 and Ríos 2008). Working as paid laborers shields farmers from some of the risk of eradication and crop loss. Furthermore, legal crops also expose cultivators to a substantial amount of risk. For example, anecdotal evidence suggests that while peaches and avocados represent alternatives for poppy growers in Guerrero, poor roads increase the probability that harvested crops will spoil before reaching market (Chandler 2015). In contrast, drug crops are often transported by drug cartels.
} 
of the maize price interaction on all of our main outcomes. The size of the cartel effect is smaller than the baseline estimate. But this is not surprising as the most dramatic increase in cartel in-fighting occurred over the last part of our full sample period, which is omitted from this specification. This again casts doubt on the idea that trend changes after 2005 drive our estimates.

In Panel $\mathrm{C}$, we address the concern that enforcement policies may vary from year to year across different regions of Mexico. Though we are not able to observe these policies directly, we divide Mexico into five geographic regions and include region by year effects as controls. This specification also constitutes a fairly stringent check, as it produces estimates identified solely off of differential within-region outcomes. We continue to find strong effects on all main outcomes under this approach.

Finally, in Appendix Table A.18, we undertake one additional robustness check that relates to the source of time variation used in our analysis. Since our estimation strategy uses both annual-level variation in prices and municipal-level variation in maize suitability, we check our main results across five specifications by clustering two-way on municipality and year. Almost all coefficients retain their statistical significance within any given specification. Effects on marijuana eradication, any cartel, and multiple cartels remain significant consistently across all specifications. No outcome is systematically insignificant across all specifications. For example, poppy eradication remains significant in two specifications and marijuana seizures remains significant in four specifications. Overall, these results suggests that this alternate clustering strategy does not change our results in a fundamental manner.

\subsection{Other Crop Suitabilities}

If maize suitability is correlated with suitability for other crops whose prices covary with the maize price, this could confound our interpretation. For example, if barley suitability is positively correlated with maize suitability, and the price of barley rises (falls) with the price of maize, this would bias our estimated effects upwards (downwards). To address this, we gather FAO suitability measures for 15 other crops besides maize, which rank among the top 30 most important agricultural commodities in Mexico in terms of production value. ${ }^{50}$ We utilize two strategies to control for these crops. In our preferred approach, we use a principal components analysis to identify the first, second and third principal components of the crop suitability data for all crops except beans and sorghum, since they are highly correlated with maize suitabil-

\footnotetext{
${ }^{50}$ These crops are wheat, barley, carrots, pasture grass, sorghum, rice, alfalfa, banana, cotton, oats, onions, potatoes, soybeans, tomatoes, and beans.
} 
ity. ${ }^{51}, 52$ The first three components together account for over $80 \%$ of the joint variation in these suitabilities. In Table 8, we add separate interactions between the three components and a full set of year dummies to flexibly control for their influence on drug crop production. The estimated effects in this specification are similar to baseline values, suggesting that overall, changing returns to legal crop suitabilities do not confound our estimates.

An alternate strategy is to include the interactions of these crop suitabilities individually with year indicators. This is less efficient, as it adds 315 additional control variables that pick up much of the variation used to identify our difference-in-differences effects. This is especially a concern since incorporating some suitabilities may already be an over-control if they are highly correlated with maize suitability. Adding these interactions may generate instability in the estimates as the effect of the maize price is identified off of less and less variation.

As shown in Appendix Figure A.2, adding each suitability individually doesn't alter any of the eradication estimates, until we add sorghum suitability (which is most highly correlated with maize suitability, with a correlation coefficient of .67). Then, for both marijuana and poppy eradication, the coefficients jump in magnitude toward zero and become insignificant. When the suitabilities are added cumulatively, the estimates remain significant for marijuana eradication, even when all 15 suitability interactions are added in. For poppy eradication, the point estimates remain stable up to the addition of 10 crop interactions. However, they attenuate and become consistently insignificant when the last five crops most highly correlated with maize suitability are added in. We discuss these points further in Appendix Section A.3. Overall, these estimates corroborate that our results are robust to controlling for the year-specific effects of a wide range of crops.

Another natural concern emerges if municipios with high maize suitability are also well suited to growing drug crops. Suppose this is true and the drug trade has expanded over time for reasons unrelated to price changes. Since maize prices are falling for most of our sample period, we might then expect to find the same difference-in-differences results even in the absence of income changes. To account for this, we re-estimate our baseline specifications but now include as controls interactions between annual dummies and the average value of the dependent variable over the period 1990-1993. These results are shown in Table 9. When examining cartel outcomes, we include the interaction of year dummies with both average marijuana and poppy eradication from 1990-1993. For all outcomes, the new point estimates are quite similar to the baseline values.

\footnotetext{
${ }^{51}$ Retention of the first three principal components of the suitability data is consistent with the Kaiser rule, which suggests that one should retain all components with associated eigenvalues above 1 . In our application only the first three principal components meet this criterion.

${ }^{52}$ The correlation between maize suitability and bean suitability is .6. The next most correlated crop is alfalfa, with a correlation coefficient of .39 .
} 


\subsection{Evolution of Drug Prices}

Our empirical specifications do not include illegal drug prices, despite their obvious importance in explaining drug production. Anecdotal accounts suggest that the economic returns to drug crop cultivation are substantially higher than returns in the legal sector. ${ }^{53}$ Yet, two limitations prevent us from exploiting drug prices in our empirical strategy. First, no data series track the farm gate prices received by rural cultivators of drug crops. Second, the price of drugs is inherently endogenous, and supply shifters like the returns to legal activities will necessarily affect the equilibrium drug price.

Our existing specifications allow us to identify the average total effect of exogenous changes in the maize price, including general equilibrium effects. Section A.5 of the Appendix provides an extended discussion of the likely consequences of omitting drug prices from our analysis. Our results will be biased if the drug price is evolving in response to exogenous factors that happen to be correlated with the maize price. The retail prices of both marijuana and heroin were falling over the period 1990-2005, and a back of the envelope calculation suggests that the falling maize price can explain much of this through general equilibrium effects. (57\% of the fall in the marijuana price and $52 \%$ of the fall in the heroin price). Nevertheless, it appears that drug prices were falling over this period for additional exogenous reasons. If anything, this should attenuate our results, since the monetary incentives to grow drugs were falling along with the price of maize.

\subsection{Other Agricultural Policies}

As described in Section 2.2, NAFTA contributed to maize price declines during our study period, and introduced other policy changes to the Mexican agricultural sector. Perhaps the most dramatic of these changes was the dismantlement of CONASUPO, a state agency which administered agricultural support and purchased and stored commodities from smallholders to guarantee demand. CONASUPO also directly marketed certain products through its retail arm, DICONSA. This raises the possibility that our results are driven not by income shocks related to price fluctuations, but by the disruption of rural market structure stemming from this policy change. This is unlikely since we rely on exogenous variation in maize prices brought about by weather shocks and fluctuations in export volumes. These factors should not be correlated with the pace of internal agricultural reform in Mexico.

However, we can also control for time-trends by CONASUPO presence. We take the average number of DICONSA stores located in a municipio over 1994-1996 as a cross-sectional

\footnotetext{
${ }^{53}$ Ríos (2008) suggests that day laborers working in the drug sector receive daily wages that are approximately six times those received by laborers working on maize farms.
} 
measurement of CONASUPO's activity within a particular municipio. ${ }^{54}$ In Panel A of Table 10, we re-estimate our basic specifications adding interactions between year dummies and this measure to control for the shift in market structure brought on by agricultural reform. All of the coefficients in these specifications are similar to the baseline estimates, suggesting that our results are not primarily driven by the elimination of CONASUPO.

Post-NAFTA agricultural reforms also reallocated state support from small-holders to commercial maize producers located largely in the North. Most state resources for maize support have been concentrated on assisting commercial maize operations in the state of Sinaloa. For example $70 \%$ of the marketing subsidies currently targeted at maize producers go to farmers in that state (Yunez-Naude and Serrano-Cote 2010). Since Sinaloa has historically been a major hub for drug activity, our results could be biased if the shift in agricultural policy coincides with the escalation of the drug trade there. To rule out this account, we re-estimate our main specifications in Panel B of Table 10 excluding Sinaloa from the sample. This sample restriction does not alter the results.

\section{Conclusion}

This paper examines how maize price dynamics affect the drug trade in Mexico. Using data from 1990-2010, we demonstrate that price changes induce differential drug market outcomes across municipios of varying maize suitability. We instrument the Mexican maize price with the maize exports of China, France and Argentina, and weather conditions in the United States Corn Belt. We include a number of controls and sample restrictions to address concerns regarding targeting of enforcement and diverging trends across different parts of Mexico.

We show effects along the entire narco-trafficking chain, starting with increases in illicit drug crops and ending with cartel violence. In particular, we document impacts on the cultivation of marijuana and opium poppies, as well as seizures of raw marijuana. These effects are larger in municipios more suited to cultivating drug crops. In addition, adverse maize price shocks influence the location of drug cartels, and exert large effects on drug-war related killings at the end of our sample period. Our results suggest that the economic impact of price changes on households and their subsequent decisions to grow illicit crops ultimately affect the industrial organization of violence in Mexico.

Our findings hold two important implications. First, they show that illicit crop cultivation responds to the returns to legal alternatives, demonstrating that production in drug markets

\footnotetext{
${ }^{54}$ Our aim is to create a variable which measures the prevalence of DICONSA at the start of our sample period since the scope and role of CONASUPO changes over time. The earliest year for which DICONSA data are available is 1994, and we average over two more years to create a more complete measure in the face of missing data.
} 
functions like production in any other market. This challenges the conventional wisdom of emphasizing law enforcement measures over policies influencing rural households, such as price and income supports. Moreover, our results reveal a previously overlooked linkage between drug cartels and cultivators: policies designed to mitigate household economic shocks may ultimately influence the operations and geographic locations of cartels.

Our results can also be used to estimate the consequences of policy changes such as NAFTA. The estimates in Ávalos-Sartorio (2006) suggest that the provisions of NAFTA effected a $20 \%$ reduction in the maize price faced by Mexican producers. ${ }^{55}$ Since maize prices fell by $59 \%$ over this period, a back of the envelope estimate suggests that about one-third of our estimated effects on drug production can be attributed to policy change. NAFTA was implemented with the hope that ensuing price changes would re-allocate workers into export-oriented sectors. While Mexican manufacturing has expanded, our results indicate that the reduction in maize prices following the Agreement may have also contributed to the growth of the illicit drug sector. Policies that alter agricultural supports or increase the exposure of rural households to international prices may have similar effects.

Our analysis highlights the importance of better understanding the economic determinants of drug supply, as well as the development consequences of the narcotics trade. Beyond factors affecting the rural economy, how do economic shocks to urban areas affect drug production? Does the expansion of the drug sector divert labor and other resources away from manufacturing? Would stronger law-enforcement institutions prevent such diversion and therefore promote the efficacy of structural reforms? These questions should be explored in future research.

\section{References}

[1] Acemoglu, Daron, Simon Johnson and James A. Robinson. 2001. "The Colonial Origins of Comparative Development: An Empirical Investigation." American Economic Review. 91(5): 1369-1401.

[2] Andreas, Peter. 1996. "U.S.-Mexico: Open Markets, Closed Border." Foreign Policy 103: 51-69.

[3] Angrist, Joshua D., and Adriana Kugler. 2008. "Rural Windfall or a New Resource Curse? Coca, Income and Civil Conflict in Colombia." Review of Economics and Statistics. 90(2): $191-215$.

${ }^{55}$ Ávalos-Sartorio (2006) estimates that in the pre-NAFTA era, Mexican policies caused the domestic producer price to be $47 \%$ higher than the international price. The transformation of these policies under NAFTA reduced this premium to only $27 \%$, yielding a $20 \%$ change. Using a separate methodology, Prina (2013) provides a very similar estimate of the effect of NAFTA on the maize price. 
[4] Astorga, Luis. 2005. El siglo de las drogas. Mexico City: Plaza y Janés.

[5] Astorga, Luis. 2007. Seguridad, traficantes y militares. Mexico City: Tusquets Editores.

[6] Ávalos-Sartorio, Beatriz. 2006. "What can we learn from past price stabilization policies and market reform in Mexico?." Food Policy 31(4): 313-327.

[7] Bazzi, Samuel and Christopher Blattman. 2014. "Economic Shocks and Conflict: The (Absence of) Evidence from Commodity Prices." American Economic Journal: Macroeconomics. 6(4).

[8] Bartra, Roger. 2012. "La Hidra Mexicana: El Retorno del PRI." Letras Libres, January.

[9] Becker, Gary S. 1968. "Crime and Punishment: An Economic Approach." Journal of Political Economy. 76(2): 169-217.

[10] Berman, Nicolas and Matthew Couttenier. 2013. "External shocks, internal shots: the geography of civil conflicts." Mimeo, University of Lausanne.

[11] Besley, Tim, Persson, Torsten, 2008. "The Incidence of Civil War: Theory and Evidence." NBER Working Paper 14585.

[12] Besley, Tim and Torsten Persson. 2009. "Repression or Civil War." American Economic Review Papers and Proceedings 99(2): 292-297.

[13] Besley, Tim and Torsten Persson. 2010. "State Capacity, Conflict and Development." Econometrica. 78: 1-34.

[14] Besley, Timothy and Torsten Persson. 2011. "The Logic of Political Violence." Quarterly Journal of Economics. 126: 1411-1445.

[15] Booth, William. 2012. "Mexico's crime wave has left about 25,000 missing, government documents show" The Washington Post: November 29.

[16] Brückner, Markus and Antonio Ciccone. 2010. "International Commodity Prices, Growth and the Outbreak of Civil War in Sub-Saharan Africa." The Economic Journal. 120(544): 519-534.

[17] Castillo, Juan Camilo, Daniel Mejia and Pascual Restrepo. 2013. "Illegal Drug Markets and Violence in Mexico: The causes beyond Calderon." Mimeo, Universiadad de Los Andes. 
[18] Chandler, Matt. March 12, 2015. "Government neglect drives Mexico's poppy farmers into drug trade." Al Jazeera America, http://america.aljazeera.com/articles/2015/3/ 12/government-neglect-pushes-mexicos-poppy-farmers-into-drug-trade.html, Last Accessed: May 23, 2015.

[19] Collier, Paul, and Anke Hoeffler. 1998. "On Economic Causes of Civil War." Oxford Economic Papers. 50: 563-73.

[20] Coscia, Michele and Viridiana Rios. 2012. "Knowing Where and How Criminal Organizations Operate Using Web Content", 21st ACM International Conference on Information and Knowledge Management (CIKM 2012).

[21] Dal Bó, Ernesto, and Pedro Dal Bó. 2011. "Workers, Warriors and Criminals: Social Conflict in General Equilibrium." Journal of the European Economic Association. 9(4): 646-677.

[22] de Janvry, Alain, Elisabeth Sadoulet and Gustavo Gordillo de Anda. 1995. "NAFTA and Mexico's maize producers." World Development. 23(8): 1349-1362.

[23] Dell, Melissa. Forthcoming. "Trafficking Networks and the Mexican Drug War" American Economic Review.

[24] Díaz-Cayeros, Alberto, Beatriz Magaloni, Aila Matanock, and Vidal Romero. 2011. "Living in Fear: Mapping the Social Embeddedness of Drug Gangs and Violence in Mexico." Mimeo, Stanford University.

[25] Do, Quy-Toan, and Lakshmi Iyer. 2010. "Geography, Poverty and Conflict in Nepal." Journal of Peace Research. 47(6): 735-748.

[26] Dube, Arindrajit, Oeindrila Dube and Omar García-Ponce. 2013. "Cross-Border Spillover: U.S. Gun Laws and Violence in Mexico" American Political Science Review. 107(3): 397417.

[27] Dube, Oeindrila and Juan Vargas. 2013. "Commodity Price Shocks and Civil Conflict: Evidence from Colombia" Review of Economic Studies. 80 (4): 1384-1421.

[28] Durante, Ruben and Emilio Gutierrez. "Fighting Crime with a Little Help from my Friends: Party Affiliation, Inter-jurisdictional Cooperation and Crime in Mexico." Sciences Po Working Paper.

[29] Eakin, Hallie. 2006. Weathering Risk in Rural Mexico: Climatic, Institutional, and Economic Change. University of Arizona Press. 
[30] Escalante, Fernando. 2009. "Territorios violentos". Nexos. http://www.nexos.com.mx/?Article $=56102 \& \mathrm{P}=$ leerarticulo.

[31] Esteban, Joan, and Debraj Ray. 2008. "On the Salience of Ethnic Conflict." American Economic Review. 98(5): 2185-2202.

[32] Federal Bureau of Investigation (FBI). 2012. Uniform Crime Reports.

[33] Food and Agricultural Organization of the United Nations (FAO). 2012a. FAOSTAT Online Database. Available at http://faostat.fao.org/

[34] Food and Agricultural Organization of the United Nations (FAO). 2012b. Global AgroEcological Zones (GAEZ v3.0). Available at http://gaez.fao.org/

[35] Fearon, James D., and David Laitin. 2003. "Ethnicity, Insurgency, and Civil War." American Political Science Review. 97: 75-90.

[36] Fearon, James D. 2005. "Primary Commodities Exports and Civil War." Journal of Conflict Resolution. 49(4): 483-507.

[37] Fries, Arthur, Robert W. Anthony, Andrew Cseko, Jr., Carl C. Gaither, and Eric Schulman. 2008. "The Price and Purity of Illicit Drugs: 1981-2007" Institute for Defense Aanalyses (IDA) Paper P-4369

[38] General Accountability Office (GAO). 1998. "Drug Control: U.S.-Mexican Counternarcotics Efforts Face Difficult Challenges." Report to Congressional Requesters. GAO/NSIAD-98-154.

[39] Global Commission on Drug Policy. 2011. "Report of the Global Commission on Drug Policy."

[40] Grossman, Herschel. 1991. "A General Equilibrium Model of Insurrections." American Economic Review. 81(4): 912-921.

[41] Grossman, Herschel. 1999. "Kleptocracy and Revolutions." Oxford Economic Papers. 51: 267-283.

[42] Guerrero, Eduardo. 2010. "Cómo reducir la violencia en M exico," Nexos.

[43] Guerrero, Eduardo. 2011. "La raíz de la violencia," Nexos.

[44] Gwande, Kishore, Devesh Kapur and Shanker Satyanath. 2012. "Natural Resource Shocks and Conflict in India's Red Belt." Mimeo, New York University. 
[45] Hall, Robert, and Chad Jones. 1999 "Why Do Some Countries Produce So Much More Output per Worker than Others?" Quarterly Journal of Economics. 114(1): 83-116.

[46] Hidalgo, Daniel, Suresh Naidu, Simeon Nichter, and Neal Richardson. 2010. "Economic Determinants of Land Invasions." Review of Economics and Statistics. 92(3): 505-523.

[47] Hirshleifer, Jack. 1991. "The Technology of Conflict as an Economic Activity." American Economic Review Papers and Proceedings. 81(2): 130-134.

[48] Humphrey, Chris. 2003. "Narcotics, Economics and Poverty in the Southern States," Policy Note 17 in the Mexico Southern States Development Strategy, Washington DC: World Bank.

[49] Ibanez, Marcela, and Fredrik Carlsson. 2010. "A survey-based choice experiment on coca cultivation." Journal of Development Economics 93(2): 249-263.

[50] Ibanez, Marcela, and Peter Martinsson. 2013. "Curbing coca cultivation in Colombia - A framed experiment." Journal of Public Economics. 105(1): 1-10.

[51] INEGI. 2011. Sistema Estatal y Municipal de Bases de Datos. Retrieved from: http://sc.inegi.org.mx/sistemas/cobdem/

[52] Kan, Paul Rexton. 2012. Cartels at War. Potomac Books.

[53] Kilmer, Beau, and Jonathan P. Caulkins, and Brittany M. Bond, and Peter H. Reuter. 2010 "Reducing Drug Trafficking Revenues and Violence in Mexico: Would Legalizing Marijuana in California Help?" RAND Occasional Paper, http://www.rand.org/ content/dam/rand/pubs/occasional_papers/2010/RAND_OP325.pdf. Last Accessed: May 23, 2015.

[54] Knight, Alan. 2012. "Nacro-Violence and the State in Modern Mexico" in Violence, coercion, and state-making in twentieth-century Mexico: The other half of the centaur. ed. W.G. Pansters. Stanford University Press.

[55] Levy, Santiago. 2008. Good Intentions, Bad Outcomes: Social Polcy, Informality, and Economic Growth in Mexico Brookings Institution Press.

[56] Lind, Jo Thori, Karl O. Moene and Fredrik Willumsen. forthcoming. "Opium for the Masses? Conflict-induced narcotics production in Afghanistan." Review of Economics and Statistics.

[57] Luhnow, David and Jose de Cordoba. 2009. "The Drug Lord Who Got Away", The Wall Street Journal, June 13. 
[58] Maldonado Aranda, Salvador. 2012. "Drogas, violencia y militarización en el México rural. El caso de Michoacán." Revista Mexicana de Sociología. 74(1): 5-39.

[59] Maystadt, Jean-François, Giacomo De Luca, Petros Sekeris and John Ulimwengu. forthcoming. "Mineral Resources and Conflicts in DRC: A Case of Ecological Fallacy." Oxford Economic Papers.

[60] Mejia, Daniel and Pascual Restrepo. 2011. "The War on Illegal Drug Production and Trafficking: An Economic Evaluation of Plan Colombia." Mimeo, Universiadad de Los Andes.

[61] Mejia, Daniel and Pascual Restrepo. 2013. "Bushes and Bullets: Illegal Cocaine Markets and Violence in Colombia." CEDE Working paper No. 1657-7191.

[62] Merino, José. 2011. "Los operativos conjuntos y la tasa de homicidios: Una Medición" Nexos, June.

[63] Meteorological Development Laboratory / Office of Science and Technology / National Weather Service / NOAA / U.S. Department of Commerce. 1987, updated half-yearly. TDL U.S. and Canada Surface Hourly Observations, daily from December 1976 to present. Research Data Archive at the National Center for Atmospheric Research, Computational and Information Systems Laboratory. http://rda.ucar.edu/datasets/ds472.0/ Accessed May 28, 2015.

[64] Miguel, Edward, Shanker Satyanath, and Ernest Sergenti. 2004. "Economic Shocks and Civil Conflict: An Instrumental Variables Approach" Journal of Political Economy. 112(4): 725-753.

[65] Mitra, Anirban and Debraj Ray. forthcoming. "Implications of an Economic Theory of Conflict: Hindu-Muslim Violence in India." Journal of Political Economy.

[66] Moreno-Sanchez, Rocio, David S. Kraybill, and Stanley R. Thompson. 2003. "An Econometric Analysis of Coca Eradication Policy in Colombia "World Development. 31(2)): 375-383.

[67] Morris, M. L. 1998. "Overview of the World Maize Economy" In: Maize Seed Industries in Developing Countries.

[68] Munro, Edith. 2012. "Eye on Argentine Exports : A country that produces less corn than Indiana is a tough competitor" Corn + Soybean Digest. November 29. http://cornandsoybeandigest.com/marketing/ 
eye-argentine-exports-country-produces-less-corn-indiana-tough-competitor Last Accessed: May 26, 2015

[69] Nájar, Alberto. 2009. "México: campesinos en las redes del narco." BBC World: November 5 .

[70] North, Douglass. 1990. Institutions, Institutional Change and Economic Performance. New York: Cambridge University Press.

[71] Nunn, Nathan and Nancy Qian. 2014. "U.S. Food Aid and Civil Conflict." American Economic Review 104 (6): 1630-1666.

[72] Nunn, Nathan and Nancy Qian. 2011. "The Impact of Potatoes on Old World Population and Urbanization." The Quarterly Journal of Economics. 126 (2): 593-650.

[73] O’Neil, Shannon. 2009. "The Real War in Mexico: How Democracy Can Defeat the Drug Cartels." Foreign Affairs, July/August.

[74] Osorio, Javier. 2012. "Democratization and Drug violence in Mexico." Working Paper. University of Notre Dame.

[75] Prina, Silvia. 2013. "Who Benefited More from the North American FreeTrade Agreement: Small or Large Farmers? Evidence from Mexico." Review of Development Economics, 17(3): 594-608.

[76] Qian, Nancy. 2008. "Missing Women and the Price of Tea in China: The Effect of SexSpecific Income on Sex Imbalance." The Quarterly Journal of Economics. 123 (3): 12511285.

[77] Ravelo, Ricardo. 2008. Los Capos, Las narco-rutas de Mexico. Grijalbo.

[78] Río Doce. 2012. "Mariguana, la única inversión segura" http://riodoce.mx/?joomla=/content/view/14774/1/

[79] Ríos, Viridiana and David A. Shirk. 2011. "Drug Violence in Mexico: Data and Analysis Through 2010." Trans-Border Institute, University of San Diego.

[80] Ríos, Viridiana 2008. "Evaluating the economic impact of Mexico's drug trafficking industry." Unpublished Manuscript, Harvard University, Department of Government.

[81] Schlenker, Wolfram,and Michael J. Roberts. 2009. "Nonlinear temperature effects indicate severe damages to U.S. crop yields under climate change. "Proceedings of the National Academy of Sciences. 106 (37): 15594-15598. 
[82] Seelke, Clare Ribando, and Kristin Finklea 2014. "U.S.-Mexican Security Cooperation: The Merida Initiative and Beyond " Congressional Research Service Report for Congress.

[83] Steinberg, Michael K. 2004. "The Marijuana Milpa: Agricultural Adaptations in a Postsubsistence Maya Landscape in Southern Belize. in "Dangerous Harvest: Drug Plants and the Transformation of Indigenous Landscapes. Oxford University Press.

[84] Stevens, Stanley C. "Boom and Bust in the '90s: The Story as Told by Corn" Journal of the ASFMRA 2000 pp. 23-28.

[85] STRATFOR Global Intelligence Security Weekly. 2013. "Mexico's Drug War: Persisting Violence and a New President" January 17.

[86] Tannura, Michael A., Scott H. Irwin, and Darrel L. Good. 2008 "Weather, Technology, and Corn and Soybean Yields in the U.S. Corn Belt" Marketing and Outlook Research Report 2008-01, Department of Agricultural and Consumer Economics, University of Illinois at Urbana-Champaign.

[87] Toro, María Celia. 1995. Mexico's War on Drugs. Causes and Consequences. Boulder: Lynne Rienner.

[88] Trostle, Ronald. 2008. "Global Agricultural Supply and Demand: Factors Contributing to the Recent Increase in Food Commodity Prices" United States Department of Agriculture. Outlook WRS-0801.

[89] United Nations (U.N.) COMTRADE. 2010. United Nations Commodity Trade Statistics Database. Available at: http://comtrade.un.org/db/

[90] United Nations (U.N.) Office of Drugs and Crime. World Drug Report 2011. United Nations Publication.

[91] United Nations (U.N.) Office of Drugs and Crime. World Drug Report 2013. United Nations Publication.

[92] United State Department of Agriculture (USDA), National Agricultural Statistics Service. 2002 2002 Census of Agriculture

[93] United States Department of Agriculture (USDA) Economic Research Service. 2013. http://www.ers.usda.gov/topics/crops/corn/trade.aspx\#.UYqIU8rIXh4

[94] United States Department of State (USDS). 2011. International Narcotics Control Strategy Report. Volume I. 
[95] United States Department of State (USDS). 2012. International Narcotics Control Strategy Report. Volume I.

[96] Wooldridge, Jeffrey. 2010. Econometric Analysis of Cross Section and Panel Data. Masschusetts Institute of Technology.

[97] Yunez-Naude, Antonio and Valeria Serrano-Cote. 2010. "Liberalization of Staple Crops: Lessons from the Mexican Experience in Maize." Journal of Agricultural Science E Technology 4(3): 95 . 
Table 1: Descriptive Statistics of Panel, Municipal, and Annual-Level Variables

\begin{tabular}{|c|c|c|c|}
\hline & Observations & Mean & Standard Deviation \\
\hline \multicolumn{4}{|l|}{ Panel-level municipal variables } \\
\hline Log marijuana eradication & 48,216 & 0.13 & 0.47 \\
\hline Log poppy eradication & 48,216 & 0.07 & 0.39 \\
\hline Log raw marijuana seizures & 48,216 & 0.17 & 0.91 \\
\hline Log processed marijuana seizures & 48,216 & 0.25 & 1.21 \\
\hline Log opium gum seizures & 48,216 & 0.01 & 0.13 \\
\hline Log heroin seizures & 48,216 & 0.002 & 0.07 \\
\hline Log cocaine and meth seizures & 48,216 & 0.03 & 0.35 \\
\hline Log total drug-related killings & 9,184 & 0.22 & 0.54 \\
\hline Log drug-related executions & 9,184 & 0.19 & 0.50 \\
\hline Log killings from confrontations & 9,184 & 0.04 & 0.24 \\
\hline Log killings from cartel attacks & 9,184 & 0.01 & 0.09 \\
\hline Log population & 48,216 & 9.19 & 1.33 \\
\hline Log detainees & 45,920 & 0.20 & 0.59 \\
\hline Temperature April-May & 48,216 & 22.37 & 4.13 \\
\hline Temperature June-July & 48,216 & 22.56 & 4.53 \\
\hline Rainfall June-July & 48,216 & 174.29 & 110.97 \\
\hline PAN mayor & 41,154 & 0.13 & 0.34 \\
\hline PRD mayor & 41,154 & 0.12 & 0.32 \\
\hline Other mayor & 41,154 & 0.03 & 0.18 \\
\hline Any cartel & 45,920 & 0.06 & 0.23 \\
\hline Multiple cartels & 45,920 & 0.03 & 0.16 \\
\hline First cartel presence & 43,158 & 0.02 & 0.12 \\
\hline \multicolumn{4}{|l|}{ Cross-sectional municipal variables } \\
\hline Maize suitability (Kg DW/ha) & 2,296 & 6.64 & 1.59 \\
\hline Log distance to security station & 2,296 & 3.08 & 0.79 \\
\hline Border indicator & 2,296 & 0.01 & 0.12 \\
\hline Ruggedness & 2,296 & 173.44 & 135.70 \\
\hline Soil workability & 2,296 & 2.25 & 1.00 \\
\hline Diconsa (1994-1996) & 2,259 & 7.94 & 11.99 \\
\hline Other crop concentration & 2,248 & 0.76 & 0.20 \\
\hline \multicolumn{4}{|l|}{ Annual-level variables } \\
\hline Log national maize price (2010 pesos) & 21 & 1.08 & 0.28 \\
\hline Log French maize exports (tons) & 21 & 15.74 & 0.16 \\
\hline Log Chinese maize exports (tons) & 21 & 14.80 & 1.73 \\
\hline Log Argentine maize exports (tons) & 21 & 15.97 & 0.49 \\
\hline U.S. freeze hours & 21 & 0.11 & 0.08 \\
\hline U.S. dew point & 21 & 63.28 & 1.74 \\
\hline U.S. temp & 21 & 74.19 & 1.96 \\
\hline Log exchange rate & 21 & 2.44 & 0.11 \\
\hline Log military expenditures & 21 & 24.37 & 0.21 \\
\hline Log armed forces personnel & 21 & 12.27 & 0.22 \\
\hline Log U.S. military aid & 21 & 16.28 & 1.59 \\
\hline
\end{tabular}

Notes : See data section for definitions of variables. 
Table 2: Maize Price, Maize Suitability, and Illicit Crops

\begin{tabular}{|c|c|c|c|c|c|c|c|c|}
\hline & (1) & (2) & (3) & (4) & (5) & (6) & (7) & (8) \\
\hline VARIABLES & $\begin{array}{c}\text { Log } \\
\text { marijuana } \\
\text { eradication }\end{array}$ & $\begin{array}{c}\text { Log } \\
\text { poppy } \\
\text { eradication }\end{array}$ & $\begin{array}{c}\text { Log } \\
\text { marijuana } \\
\text { eradication }\end{array}$ & $\begin{array}{c}\text { Log } \\
\text { poppy } \\
\text { eradication }\end{array}$ & $\begin{array}{c}\text { Log } \\
\text { marijuana } \\
\text { eradication }\end{array}$ & $\begin{array}{c}\text { Log } \\
\text { poppy } \\
\text { eradication }\end{array}$ & $\begin{array}{l}\text { Log } \\
\text { marijuana } \\
\text { eradication }\end{array}$ & $\begin{array}{c}\text { Log } \\
\text { poppy } \\
\text { eradication }\end{array}$ \\
\hline MAIZE x PRICE & $\begin{array}{c}-0.017 * * * \\
(0.005)\end{array}$ & $\begin{array}{c}-0.012 * * * \\
(0.004)\end{array}$ & $\begin{array}{c}-0.022 * * * \\
(0.005)\end{array}$ & $\begin{array}{c}-0.017^{* * *} \\
(0.004)\end{array}$ & $\begin{array}{c}-0.022 * * * \\
(0.005)\end{array}$ & $\begin{array}{c}-0.017 * * * \\
(0.004)\end{array}$ & $\begin{array}{c}-0.033 * * * \\
(0.007)\end{array}$ & $\begin{array}{c}-0.013 * * * \\
(0.005)\end{array}$ \\
\hline Weather and land quality controls? & & & & & $\mathrm{Y}$ & $\mathrm{Y}$ & $\mathrm{Y}$ & $\mathrm{Y}$ \\
\hline Municipio trends? & & & & & & & $\mathrm{Y}$ & Y \\
\hline Estimation method & OLS & OLS & IV-2SLS & IV-2SLS & IV-2SLS & IV-2SLS & IV-2SLS & IV-2SLS \\
\hline Observations & 48,279 & 48,279 & 48,279 & 48,279 & 48,216 & 48,216 & 48,216 & 48,216 \\
\hline Municipios & 2,299 & 2,299 & 2,299 & 2,299 & 2,296 & 2,296 & 2,296 & 2,296 \\
\hline
\end{tabular}

Notes : Robust standard errors clustered at the municipal level are shown in parentheses. Variables not shown and included in all regressions are: municipio and year fixed effects, log population, and the interaction of maize suitability with the (log) U.S. Mexico real exchange rate. Log marijuana and poppy eradication are measured as $\log$ of area eradicated per 10,000 hectares plus 1 . In columns $3-8$, the interaction of maize suitability and the log national maize price is instrumented with the interaction of maize suitability and lagged weather conditions in the U.S. (dewpoint, temperature, temperature squared, freeze hours, and freeze hours squared), along with the log export volumes of China, France, and Argentina. Weather and land quality controls in columns 5-8 include: temperature and rainfall conditions in Mexican municipios, and land quality interacted with year effects. Columns 7 and 8 include municipio-specific linear trends. ${ }^{* * *}$ is significant at the $1 \%$ level, $* *$ is significant at the $5 \%$ level, and $*$ is significant at the $10 \%$ level. 
Table 3: First-Stage Estimates

\begin{tabular}{lc}
\hline \hline VARIABLES & MAIZE x PRICE \\
\hline MAIZE x CHN & $-0.030^{* * *}$ \\
& $(0.000)$ \\
MAIZE x FRA & $-0.295^{* * *}$ \\
& $(0.001)$ \\
MAIZE x ARG & $-0.347^{* * *}$ \\
& $(0.000)$ \\
MAIZE x FREEZE & $-2.240^{* * *}$ \\
& $(0.004)$ \\
MAIZE x FREEZE SQ & $9.040^{* * *}$ \\
MAIZE x DEW POINT & $(0.014)$ \\
& $-0.102^{* * *}$ \\
MAIZE x TEMP & $(0.000)$ \\
F-statistic of excluded instruments: & $-1.877^{* * *}$ \\
MAIZE x TEMP SQ & $(0.004)$ \\
Weather and land quality controls? & $0.013^{* * *}$ \\
Municipio trends? & $(0.000)$ \\
Observations & $\mathrm{Y}$ \\
Municipios & $\mathrm{Y}$ \\
\end{tabular}

Notes: This is the first-stage of our baseline specification (shown in Columns 7-8 of Table 2). Though the first and second stage estimates are presented separately, the estimation has been condcuted via a onestep IV-2SLS procedure. Variables not shown in this regression are: municipio and year fixed effects, log population, the interaction of maize suitability with the (log) U.S. Mexico real exchange rate, temperature and rainfall conditions in Mexican municipios, land quality interacted with year effects, and municipio-specific linear trends. Robust standard errors clustered at the municipal level are shown in parentheses. The F-statistic refers to the Angrist-Pischke Fstatistic of excluded instruments. $* * *$ is significant at the $1 \%$ level, ** is significant at the $5 \%$ level, and * is significant at the $10 \%$ level. 
Table 4: Maize Price, Maize Suitability, and Drug Seizures

\begin{tabular}{|c|c|c|c|c|c|}
\hline & (1) & $(2)$ & (3) & (4) & (5) \\
\hline & \multicolumn{5}{|c|}{ Panel A: Sample Including Municipios Near the Border } \\
\hline & \multicolumn{2}{|c|}{ Raw outputs } & \multicolumn{3}{|c|}{ Processed outputs } \\
\hline & Marijuana & Opium gum & marijuana & Heroin & Other \\
\hline MAIZE x PRICE & $\begin{array}{l}-0.028 * \\
(0.016)\end{array}$ & $\begin{array}{c}-0.003 \\
(0.002)\end{array}$ & $\begin{array}{c}0.086 * * * \\
(0.028)\end{array}$ & $\begin{array}{c}0.001 \\
(0.002)\end{array}$ & $\begin{array}{c}0.004 \\
(0.008)\end{array}$ \\
\hline Municipio trends? & $\mathrm{Y}$ & $\mathrm{Y}$ & $\mathrm{Y}$ & $\mathrm{Y}$ & $\mathrm{Y}$ \\
\hline Observations & 48,216 & 48,216 & 48,216 & 48,216 & 48,216 \\
\hline Municipios & 2,296 & 2,296 & 2,296 & 2,296 & 2,296 \\
\hline
\end{tabular}

Panel B: Sample Without Municipios Near the Border

\begin{tabular}{|c|c|c|c|c|c|}
\hline & \multicolumn{2}{|c|}{ Raw outputs } & \multicolumn{3}{|c|}{ Processed outputs } \\
\hline & Marijuana & Opium gum & $\begin{array}{l}\text { Processed } \\
\text { marijuana }\end{array}$ & Heroin & Other \\
\hline MAIZE x PRICE & $\begin{array}{c}-0.027^{*} \\
(0.015)\end{array}$ & $\begin{array}{l}-0.003 \\
(0.002)\end{array}$ & $\begin{array}{c}0.004 \\
(0.024)\end{array}$ & $\begin{array}{c}0.002 \\
(0.001)\end{array}$ & $\begin{array}{c}0.006 \\
(0.007)\end{array}$ \\
\hline Municipio trends? & $\mathrm{Y}$ & $\mathrm{Y}$ & $\mathrm{Y}$ & $\mathrm{Y}$ & $\mathrm{Y}$ \\
\hline Observations & 45,969 & 45,969 & 45,969 & 45,969 & 45,969 \\
\hline Municipios & 2,189 & 2,189 & 2,189 & 2,189 & 2,189 \\
\hline
\end{tabular}

Notes: Robust standard errors clustered at the municipal level are shown in parentheses. Variables not shown and included in all regressions are: municipio and year fixed effects, municipio-specific linear trends, log population, the interaction of maize suitability with the (log) U.S. Mexico real exchange rate, weather and land quality controls and municipio-specific linear trends. All drug seizures are measured as the log of kilograms seized plus 1 . The "Other" category is comprised of cocaine and crystal meth seizures. The interaction of maize suitability and the log national maize price is instrumented with the interaction of maize suitability and lagged weather conditions in the U.S. (dewpoint, temperature, temperature squared, freeze hours, and freeze hours squared), along with the log export volumes of China, France, and Argentina. "Near the Border" includes municipios within 100 miles of the U.S.-Mexico border. $* * *$ is significant at the $1 \%$ level, $* *$ is significant at the $5 \%$ level, and $*$ is significant at the $10 \%$ level. 
Table 5: Heterogenous Effects on Drug Eradication

\begin{tabular}{|c|c|c|c|c|}
\hline & $\begin{array}{c}\text { (1) } \\
\text { Log marijuana } \\
\text { eradication }\end{array}$ & $\begin{array}{c}\text { (2) } \\
\text { Log poppy eradication }\end{array}$ & $\begin{array}{c}\text { (3) } \\
\text { Log marijuana } \\
\text { eradication } \\
\end{array}$ & $\begin{array}{c}\text { (4) } \\
\text { Log poppy eradication }\end{array}$ \\
\hline \multirow[t]{2}{*}{ Sample Split: } & \multicolumn{2}{|c|}{ Below Median } & \multicolumn{2}{|c|}{ Above Median } \\
\hline & \multicolumn{4}{|c|}{ Panel A: Other Crop Concentration } \\
\hline \multirow[t]{2}{*}{ MAIZE x PRICE } & $-0.030 * * *$ & -0.008 & $-0.040 * * *$ & $-0.021 * * *$ \\
\hline & $(0.009)$ & $(0.006)$ & $(0.010)$ & $(0.008)$ \\
\hline Municipio trends? & $\mathrm{Y}$ & $\mathrm{Y}$ & $\mathrm{Y}$ & $\mathrm{Y}$ \\
\hline Observations & 23,604 & 23,604 & 23,604 & 23,604 \\
\hline \multirow[t]{2}{*}{ Municipios } & 1,124 & 1,124 & 1,124 & 1,124 \\
\hline & \multicolumn{4}{|c|}{ Panel B: Marijuana Suitability } \\
\hline \multirow[t]{2}{*}{ MAIZE x PRICE } & 0.001 & 0.003 & $-0.080 * * *$ & $-0.038 * * *$ \\
\hline & $(0.005)$ & $(0.004)$ & $(0.016)$ & $(0.012)$ \\
\hline Municipio trends? & $\mathrm{Y}$ & $\mathrm{Y}$ & $\mathrm{Y}$ & $\mathrm{Y}$ \\
\hline Observations & 31,689 & 31,689 & 16,527 & 16,527 \\
\hline \multirow[t]{2}{*}{ Municipios } & 1,509 & 1,509 & 787 & 787 \\
\hline & \multicolumn{4}{|c|}{ Panel C: Poppy Suitability } \\
\hline \multirow[t]{2}{*}{ MAIZE x PRICE } & -0.004 & 0.001 & $-0.123 * * *$ & $-0.071 * * *$ \\
\hline & $(0.005)$ & $(0.003)$ & $(0.033)$ & $(0.025)$ \\
\hline Municipio trends? & $\mathrm{Y}$ & $\mathrm{Y}$ & $\mathrm{Y}$ & $\mathrm{Y}$ \\
\hline Observations & 39,921 & 39,921 & 8,295 & 8,295 \\
\hline \multirow[t]{2}{*}{ Municipios } & 1,901 & 1,901 & 395 & 395 \\
\hline & \multicolumn{4}{|c|}{ Panel D: Ruggedness } \\
\hline \multirow[t]{2}{*}{ MAIZE x PRICE } & 0.004 & -0.001 & $-0.086 * * *$ & $-0.035^{* * *}$ \\
\hline & $(0.007)$ & $(0.005)$ & $(0.013)$ & $(0.010)$ \\
\hline Municipio trends? & $\mathrm{Y}$ & $\mathrm{Y}$ & $\mathrm{Y}$ & $\mathrm{Y}$ \\
\hline Observations & 24,108 & 24,108 & 24,108 & 24,108 \\
\hline \multirow[t]{2}{*}{ Municipios } & 1,148 & 1,148 & 1,148 & 1,148 \\
\hline & \multicolumn{4}{|c|}{ Panel E: Distance to Security Station } \\
\hline \multirow[t]{2}{*}{ MAIZE x PRICE } & $-0.027 * *$ & -0.006 & $-0.038^{* * *}$ & $-0.018 * * *$ \\
\hline & $(0.011)$ & $(0.008)$ & $(0.009)$ & $(0.006)$ \\
\hline Municipio trends? & $\mathrm{Y}$ & $\mathrm{Y}$ & $\mathrm{Y}$ & $\mathrm{Y}$ \\
\hline Observations & 24,108 & 24,108 & 24,108 & 24,108 \\
\hline Municipios & 1,148 & 1,148 & 1,148 & 1,148 \\
\hline \multicolumn{5}{|c|}{$\begin{array}{l}\text { Notes: Robust standard errors clustered at the municipal level are shown in parentheses. Variables not shown and included in all } \\
\text { regressions are: municipio and year fixed effects, municipio-specific linear trends, log population, the interaction of maize } \\
\text { suitability with the (log) U.S. Mexico real exchange rate, and weather and land quality controls. Log marijuana and poppy } \\
\text { eradication are measured as log of area eradicated per } 10,000 \text { hectares plus } 1 \text {. Panels A, B, C, D, and E split the sample into below } \\
\text { and above median levels of the Herfindahl Index of other crop concentration, suitability for growing marijuana, suitability for } \\
\text { growing opium poppy, terrain ruggedness, and distance to the nearest security station, respectively. The interaction of maize } \\
\text { suitability and the log national maize price is instrumented with the interaction of maize suitability and lagged weather conditions in } \\
\text { the U.S. (dewpoint, temperature, temperature squared, freeze hours, and freeze hours squared), along with the log export volumes of } \\
\text { China, France, and Argentina. All regressions include municipio-specific linear trends. *** is significant at the } 1 \% \text { level, ** is } \\
\text { significant at the } 5 \% \text { level, and * is significant at the } 10 \% \text { level. }\end{array}$} \\
\hline
\end{tabular}


Table 6: Maize Price, Maize Suitability, and Drug Cartels

(1)

(2)

\begin{tabular}{lccc} 
VARIABLES & Any cartel & Multiple cartels & $\begin{array}{c}\text { First cartel } \\
\text { presence }\end{array}$ \\
\hline MAIZE x PRICE & $-0.028^{* * *}$ & $-0.019^{* * *}$ & $-0.016^{* * *}$ \\
& $(0.006)$ & $(0.004)$ & $(0.004)$
\end{tabular}

(0.004)

r

\section{(5)}

Log drug-

related

executions

related killings

$\begin{array}{cc}-0.334^{* * *} & -0.308^{* * *} \\ (0.086) & (0.077)\end{array}$

First Stage:

MAIZE x Generated Maize Price

Log killings

from

Log killings

confrontations attacks

-0.076
$(0.050)$

(0.050)

MAIZE x PRICE

$0.382 * * *$

(0.001)

F-statistic of excluded instruments: $\quad 3.5 \mathrm{e}+05$

\begin{tabular}{lcccccc} 
Municipio trends? & Y & Y & Y & Y & Y & Y \\
Sample period & $1991-2010$ & $1991-2010$ & $1991-2010$ & $2007-2010$ & $2007-2010$ & $2007-2010$ \\
Observations & 45,920 & 45,920 & 43,155 & 9184 & 9184 & 9184 \\
Municipios & 2,296 & 2,296 & 2,293 & 2296 & 2296 & 2296 \\
\hline \hline
\end{tabular}

Notes: Robust standard errors clustered at the municipal level are shown in parentheses. Variables not shown and included in all regressions are: municipio and year fixed effects, municipio-specific linear trends, log population, and weather and land quality controls. Any cartel, Multiple cartels, and First cartel presence are dichotomous indicators of whether a municipio has any cartel, multiple cartels, or a cartel operating for the first time, respectively, in any given year. Log total drugrelated killings, drug-related executions, killings from confrontations, and killings from cartel attacks are measured as log count per 10,000 people plus 1 . In columns $1-3$, the interaction of maize suitability and the log national maize price is instrumented with the interaction of maize suitability and lagged weather conditions in the U.S. (dewpoint, temperature, temperature squared, freeze hours, and freeze hours squared), along with the log export volumes of China, France, and Argentina. These regressions also include the interaction of maize suitability with the (log) U.S. Mexico real exchange rate. In columns 4-7, the interaction of maize suitability and log national maize price is instrumented by the interaction of maize suitability and a generated price instrument (predicted on the basis of the lagged weather conditions in the U.S. and log export volume of China, France and Argentina). The F-statistic refers to the Angrist-Pischke F-statistic of excluded instruments. *** is significant at the $1 \%$ level, ** is significant at the $5 \%$ level, and * is significant at the $10 \%$ level. 
Table 7: Accounting for Local Enforcement

\begin{tabular}{|c|c|c|c|c|c|c|c|}
\hline VARIABLES & $\begin{array}{l}\text { (1) } \\
\text { Log marijuana } \\
\text { eradication }\end{array}$ & $\begin{array}{c}\text { (2) } \\
\text { Log poppy } \\
\text { eradication }\end{array}$ & $\begin{array}{c}\text { (3) } \\
\text { Log raw } \\
\text { marijuana } \\
\text { seizures } \\
\end{array}$ & $\begin{array}{c}\text { (4) } \\
\text { Log opium } \\
\text { gum seizures }\end{array}$ & Any cartel & $\begin{array}{c}\text { (6) } \\
\text { Multiple } \\
\text { cartels }\end{array}$ & $\begin{array}{l}\text { (7) } \\
\text { First cartel } \\
\text { presence }\end{array}$ \\
\hline MAIZE x PRICE & $\begin{array}{c}-0.030 * * * \\
(0.007)\end{array}$ & $\begin{array}{l}-0.009 * \\
(0.005)\end{array}$ & $\begin{array}{c}-0.037^{* *} \\
(0.016)\end{array}$ & $\begin{array}{c}-0.004 \\
(0.003)\end{array}$ & $\begin{array}{c}-0.027^{* * *} \\
(0.006)\end{array}$ & $\begin{array}{c}-0.019 * * * \\
(0.005)\end{array}$ & $\begin{array}{c}-0.016^{* * *} \\
(0.004)\end{array}$ \\
\hline Mayor's Political Party? & $\mathrm{Y}$ & $\mathrm{Y}$ & $\mathrm{Y}$ & $\mathrm{Y}$ & $\mathrm{Y}$ & $\mathrm{Y}$ & $\mathrm{Y}$ \\
\hline Detainees? & $\mathrm{Y}$ & $\mathrm{Y}$ & $\mathrm{Y}$ & $\mathrm{Y}$ & $\mathrm{Y}$ & $\mathrm{Y}$ & Y \\
\hline Municipio trends? & $\mathrm{Y}$ & $\mathrm{Y}$ & $\mathrm{Y}$ & $\mathrm{Y}$ & $\mathrm{Y}$ & $\mathrm{Y}$ & $\mathrm{Y}$ \\
\hline Observations & 39,027 & 39,027 & 39,027 & 39,027 & 39,027 & 39,027 & 36,282 \\
\hline Municipios & 2,292 & 2,292 & 2,292 & 2,292 & 2,292 & 2,292 & 2,289 \\
\hline
\end{tabular}

Notes: Robust standard errors clustered at the municipal level are shown in parentheses. Variables not shown and included in all regressions are: municipio and year fixed effects, municipio-specific linear trends, the mayor's political party, (log) detainees plus 1, log population, the interaction of maize suitability with the (log) U.S. Mexico real exchange rate, and weather and land quality controls. Log marijuana and poppy eradication are measured as log of area eradicated per 10,000 hectares plus 1 . All drug seizures are measured as log of kilograms seized plus 1 . Any cartel, Multiple cartels, and First cartel presence are dichotomous indicators of whether a municipio has any cartel, multiple cartels, or a cartel operating for the first time, respectively, in any given year. The interaction of maize suitability and the log national maize price is instrumented with the interaction of maize suitability and lagged weather conditions in the U.S. (dewpoint, temperature, temperature squared, freeze hours, and freeze hours squared), along with the log export volumes of China, France, and Argentina. *** is significant at the $1 \%$ level, ** is significant at the $5 \%$ level, and $*$ is significant at the $10 \%$ level. 
Table 8: Accounting for Legal Crop Suitabilities

\begin{tabular}{|c|c|c|c|c|c|c|c|}
\hline VARIABLES & $\begin{array}{c}\text { (1) } \\
\text { Log } \\
\text { marijuana } \\
\text { eradication } \\
\end{array}$ & $\begin{array}{c}\text { (2) } \\
\text { Log poppy } \\
\text { eradication }\end{array}$ & $\begin{array}{c}(3) \\
\text { Log raw } \\
\text { marijuana } \\
\text { seizures } \\
\end{array}$ & $\begin{array}{c}\text { (4) } \\
\text { Log opium } \\
\text { gum } \\
\text { seizures } \\
\end{array}$ & Any cartel & $\begin{array}{c}\text { (6) } \\
\text { Multiple } \\
\text { cartels }\end{array}$ & $\begin{array}{l}\text { (7) } \\
\text { First cartel } \\
\text { presence }\end{array}$ \\
\hline MAIZE x PRICE & $\begin{array}{c}-0.028 * * * \\
(0.007)\end{array}$ & $\begin{array}{c}-0.011^{* *} \\
(0.005)\end{array}$ & $\begin{array}{c}-0.027 * \\
(0.016)\end{array}$ & $\begin{array}{c}-0.004 \\
(0.002)\end{array}$ & $\begin{array}{c}-0.022 * * * \\
(0.006)\end{array}$ & $\begin{array}{c}-0.014 * * * \\
(0.004)\end{array}$ & $\begin{array}{c}-0.015 * * * \\
(0.004)\end{array}$ \\
\hline Principal Component Controls? & $\mathrm{Y}$ & $\mathrm{Y}$ & $\mathrm{Y}$ & $\mathrm{Y}$ & $\mathrm{Y}$ & $\mathrm{Y}$ & $\mathrm{Y}$ \\
\hline Municipio Trends? & $\mathrm{Y}$ & $\mathrm{Y}$ & $\mathrm{Y}$ & $\mathrm{Y}$ & $\mathrm{Y}$ & $\mathrm{Y}$ & $\mathrm{Y}$ \\
\hline Observations & 48,216 & 48,216 & 48,216 & 48,216 & 45,920 & 45,920 & 43,155 \\
\hline Municipios & 2,296 & 2,296 & 2,296 & 2,296 & 2,296 & 2,296 & 2,293 \\
\hline
\end{tabular}

Notes: Robust standard errors clustered at the municipal level are shown in parentheses. The principal component controls include the first, second and third principal components of 13 other legal crop suitabilities, interacted with year effects. Additional variables not shown and included in all regressions are: municipio and year fixed effects, municipio-specific linear trends, log population, temperature and rainfall conditions in Mexican municipios, land quality interacted with year effects, and the interaction of maize suitability with the (log) U.S. Mexico real exchange. Log marijuana and poppy eradication are measured as log of area eradicated per 10,000 hectares plus 1 . All drug seizures are measured as log of kilograms seized plus 1.Any cartel, First cartel presence, and Multiple cartels are dichotomous indicators of whether a municipio has any cartel, a cartel operating for the first time, or multiple cartels, respectively, in any given year. The interaction of maize suitability and the log national maize price is instrumented with the interaction of maize suitability and lagged weather conditions in the U.S. (dewpoint, temperature, temperature squared, freeze hours, and freeze hours squared), along with the log export volumes of China, France, and Argentina. $* * *$ is significant at the $1 \%$ level, ** is significant at the $5 \%$ level, and * is significant at the $10 \%$ level. 
Table 9: Accounting for Drug Crop Suitability

$(1)$

\begin{tabular}{lccccccc} 
VARIABLES & $\begin{array}{c}\text { Log marijuana } \\
\text { eradication }\end{array}$ & $\begin{array}{c}\text { Log poppy } \\
\text { eradication }\end{array}$ & $\begin{array}{c}\text { Log raw } \\
\text { marijuana } \\
\text { seizures }\end{array}$ & $\begin{array}{c}\text { Log opium gum } \\
\text { seizures }\end{array}$ & Any cartel & Multiple cartels & $\begin{array}{c}\text { First cartel } \\
\text { presence }\end{array}$ \\
\hline MAIZE x PRICE & $-0.027^{* * *}$ & $-0.014^{* * *}$ & $-0.037^{* *}$ & $-0.004^{*}$ & $-0.031^{* * *}$ & $-0.021^{* * *}$ & $-0.017^{* * *}$ \\
& $(0.006)$ & $(0.005)$ & $(0.015)$ & $(0.002)$ & $(0.006)$ & $(0.004)$ & $(0.004)$ \\
Municipio trends? & $\mathrm{Y}$ & $\mathrm{Y}$ & $\mathrm{Y}$ & $\mathrm{Y}$ & $\mathrm{Y}$ & $\mathrm{Y}$ & $\mathrm{Y}$ \\
Observations & 48,216 & 48,216 & 48,216 & 48,216 & 45,920 & 45,920 & 43,155 \\
Municipios & 2,296 & 2,296 & 2,296 & 2,296 & 2,296 & 2,296 & 2,293 \\
\hline \hline
\end{tabular}

Notes: Robust standard errors clustered at the municipal level are shown in parentheses. Variables not shown and included in all regressions are: municipio and year fixed effects, log population, the interaction of maize suitability with the (log) U.S. Mexico real exchange rate, and weather and land quality controls. Log marijuana and poppy eradication are measured as log of area eradicated per 10,000 hectares plus 1 . All drug seizures are measured as $\log$ of kilograms seized plus 1 . Any cartel, Multiple cartels, and First cartel presence are dichotomous indicators of whether a municipio has any cartel, multiple cartels, or a cartel operating for the first time, respectively, in any given year. In columns $1-4$, regressions include the interaction of year effects with average dependent variable over 1990-1993. In columns 5-7, regressions include the interaction of year effects with both average marijuana and poppy eradication over 1990-1993. The interaction of maize suitability and the log national maize price is instrumented with the interaction of maize suitability and lagged weather conditions in the U.S. (dewpoint, temperature, temperature squared, freeze hours, and freeze hours squared), along with the log export volumes of China, France, and Argentina. All regressions include municipio-specific linear trends. ${ }^{* * *}$ is significant at the $1 \%$ level, $* *$ is significant at the $5 \%$ level, and * is significant at the $10 \%$ level. 
Table 10: Accounting for Other Policy Changes

\begin{tabular}{|c|c|c|c|c|c|c|c|}
\hline & (1) & $(2)$ & (3) & (4) & (5) & (6) & (7) \\
\hline \multirow[t]{2}{*}{ VARIABLES } & $\begin{array}{l}\text { Log marijuana } \\
\text { eradication }\end{array}$ & $\begin{array}{l}\text { Log poppy } \\
\text { eradication }\end{array}$ & $\begin{array}{c}\text { Log raw } \\
\text { marijuana } \\
\text { seizures }\end{array}$ & $\begin{array}{l}\text { Log opium gum } \\
\text { seizures }\end{array}$ & Any cartel & Multiple cartels & $\begin{array}{c}\text { First cartel } \\
\text { presence }\end{array}$ \\
\hline & \multicolumn{7}{|c|}{ Panel A: Controlling for Diconsa Stores 1994-1996 Interacted with Year Effects } \\
\hline \multirow[t]{2}{*}{ MAIZE x PRICE } & $-0.036 * * *$ & $-0.015^{* * *}$ & $-0.028 *$ & -0.003 & $-0.024 * * *$ & $-0.015^{* * *}$ & $-0.013 * * *$ \\
\hline & $(0.007)$ & $(0.005)$ & $(0.017)$ & $(0.002)$ & $(0.006)$ & $(0.004)$ & $(0.004)$ \\
\hline Municipio trends? & $\mathrm{Y}$ & $\mathrm{Y}$ & $\mathrm{Y}$ & $\mathrm{Y}$ & $\mathrm{Y}$ & $\mathrm{Y}$ & $\mathrm{Y}$ \\
\hline Observations & 47,439 & 47,439 & 47,439 & 47,439 & 45,180 & 45,180 & 42,574 \\
\hline \multirow[t]{2}{*}{ Municipios } & 2,259 & 2,259 & 2,259 & 2,259 & 2,259 & 2,259 & 2,256 \\
\hline & \multicolumn{7}{|c|}{ Panel B: Excluding the State of Sinaloa } \\
\hline \multirow[t]{2}{*}{ MAIZE x PRICE } & $-0.035 * * *$ & $-0.013 * * *$ & $-0.035 * *$ & -0.003 & $-0.031 * * *$ & $-0.022 * * *$ & $-0.017 * * *$ \\
\hline & $(0.007)$ & $(0.005)$ & $(0.015)$ & $(0.002)$ & $(0.006)$ & $(0.004)$ & $(0.004)$ \\
\hline Municipio trends? & $\mathrm{Y}$ & $\mathrm{Y}$ & $\mathrm{Y}$ & $\mathrm{Y}$ & $\mathrm{Y}$ & $\mathrm{Y}$ & $\mathrm{Y}$ \\
\hline Observations & 47,901 & 47,901 & 47,901 & 47,901 & 45,620 & 45,620 & 42,984 \\
\hline Municipios & 2,281 & 2,281 & 2,281 & 2,281 & 2,281 & 2,281 & 2,280 \\
\hline
\end{tabular}

Notes: Robust standard errors clustered at the municipal level are shown in parentheses. Variables not shown and included in all regressions are: municipio and year fixed effects, municipio-specific linear trends, log population, the interaction of maize suitability with the (log) U.S. Mexico real exchange rate, and weather and land quality controls. Log marijuana and poppy eradication are measured as log of area eradicated per 10,000 hectares plus 1 . All drug seizures are measured as log of kilograms seized plus 1 . Any cartel, Multiple cartels, and First cartel presence are dichotomous indicators of whether a municipio has any cartel, multiple cartels, or a cartel operating for the first time, respectively, in any given year. In Panel A, all regressions include the average number of Diconsa stores between 1994 and 1996 interacted with year effects. In Panel B, the state of Sinaloa is excluded from all regressions. The interaction of maize suitability and the log national maize price is instrumented with the interaction of maize suitability and lagged weather conditions in the U.S. (dewpoint, temperature, temperature squared, freeze hours, and freeze hours squared), along with the log export volumes of China, France, and Argentina. *** is significant at the $1 \%$ level, ** is significant at the $5 \%$ level, and * is significant at the $10 \%$ level. 
Figure 1: Maize Prices

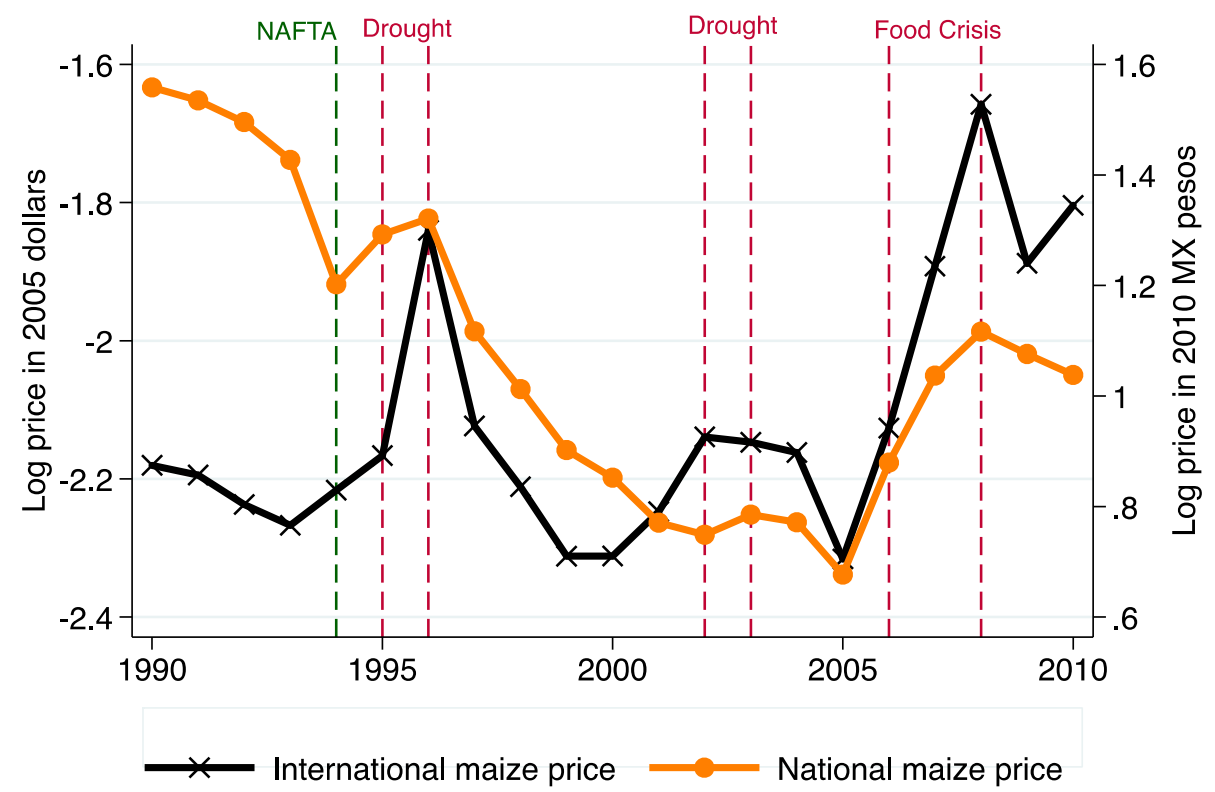

Notes: This figure shows the international maize price and Mexican maize price over the 1990-2010 period. The data for the international price come from the World Bank. The data for the national price come from the Servicio de Información Agroalimentaria y Pesquera (SIAP), in the Mexican Ministry of Agriculture. The green line marks the introduction of NAFTA in 1994. The red lines denote U.S. droughts and the international food crisis. 
Figure 2: Drug Crop Eradication in Mexico

\section{Panel A: Average Eradication of Marijuana in Mexican Municipios}

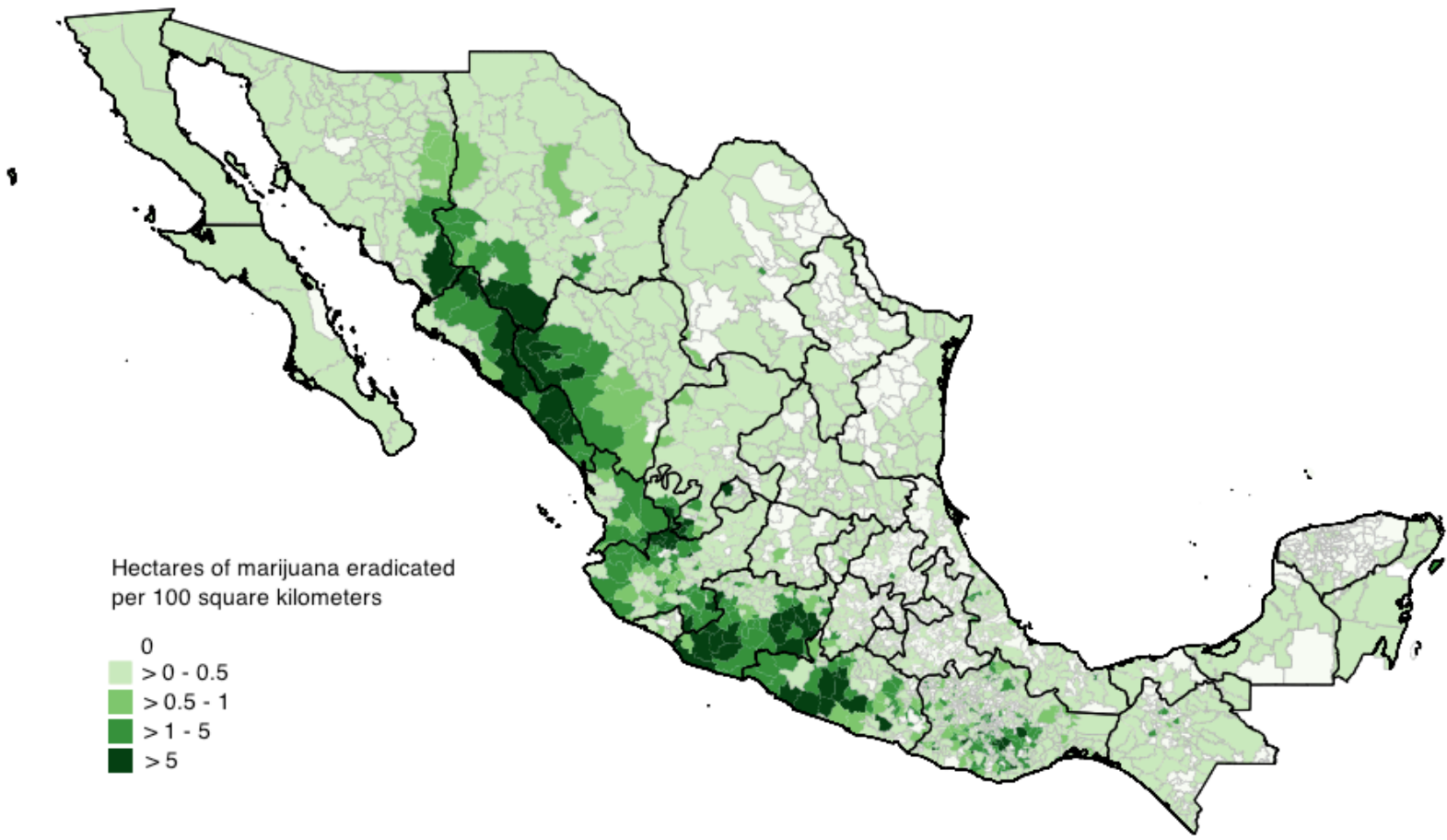

\section{Panel B: Average Eradication of Poppy in Mexican Municipios}

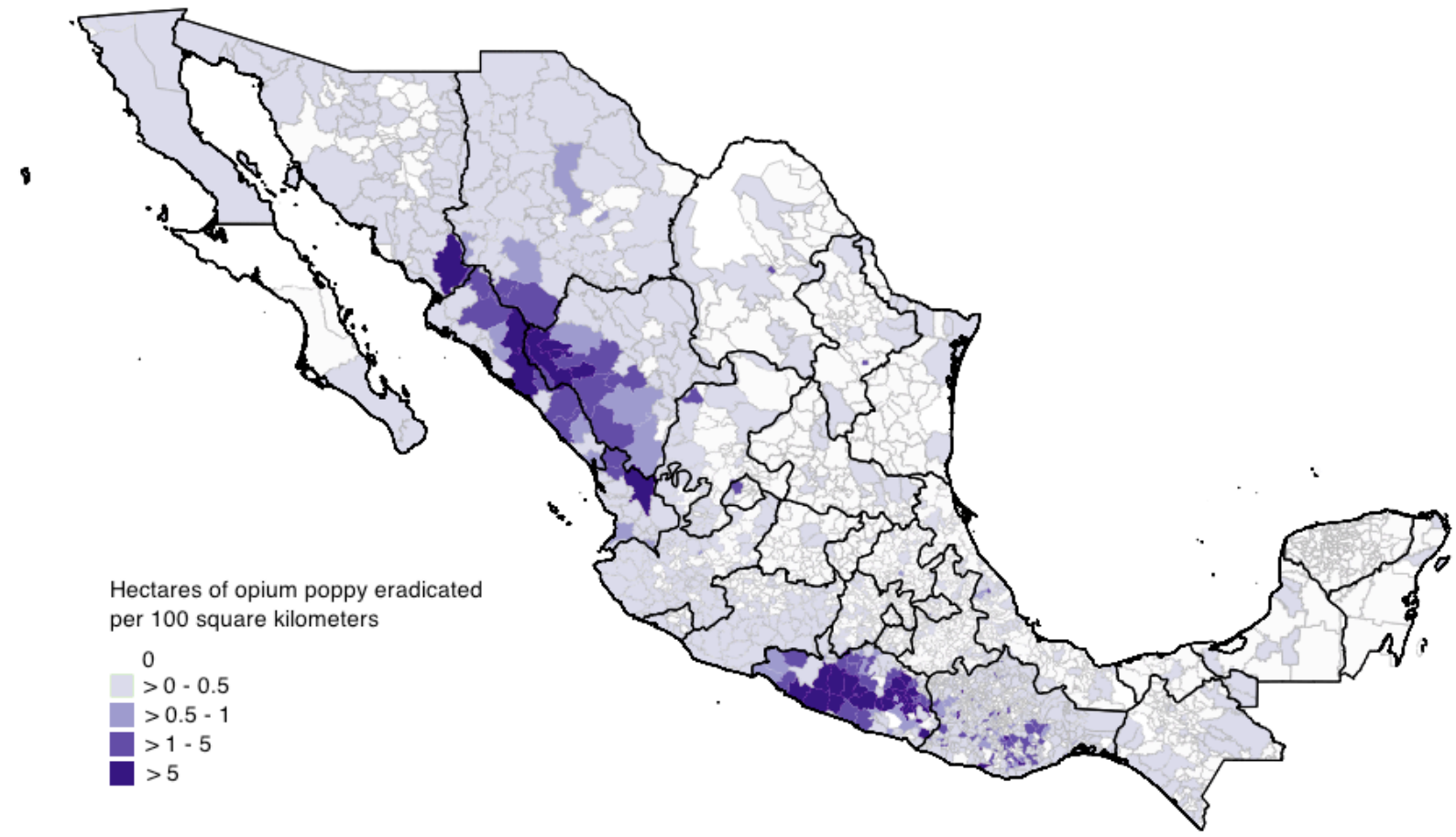

Notes: This figure shows annual averages of marijuana (Panel A) and poppy (Panel B) eradicated per 100 square $\mathrm{km}$. in each Mexican municipio between 1990 and 2010. The data were obtained from SEDENA. Darker colors denote higher levels of eradication. 
Figure 3: Drug-related Killings

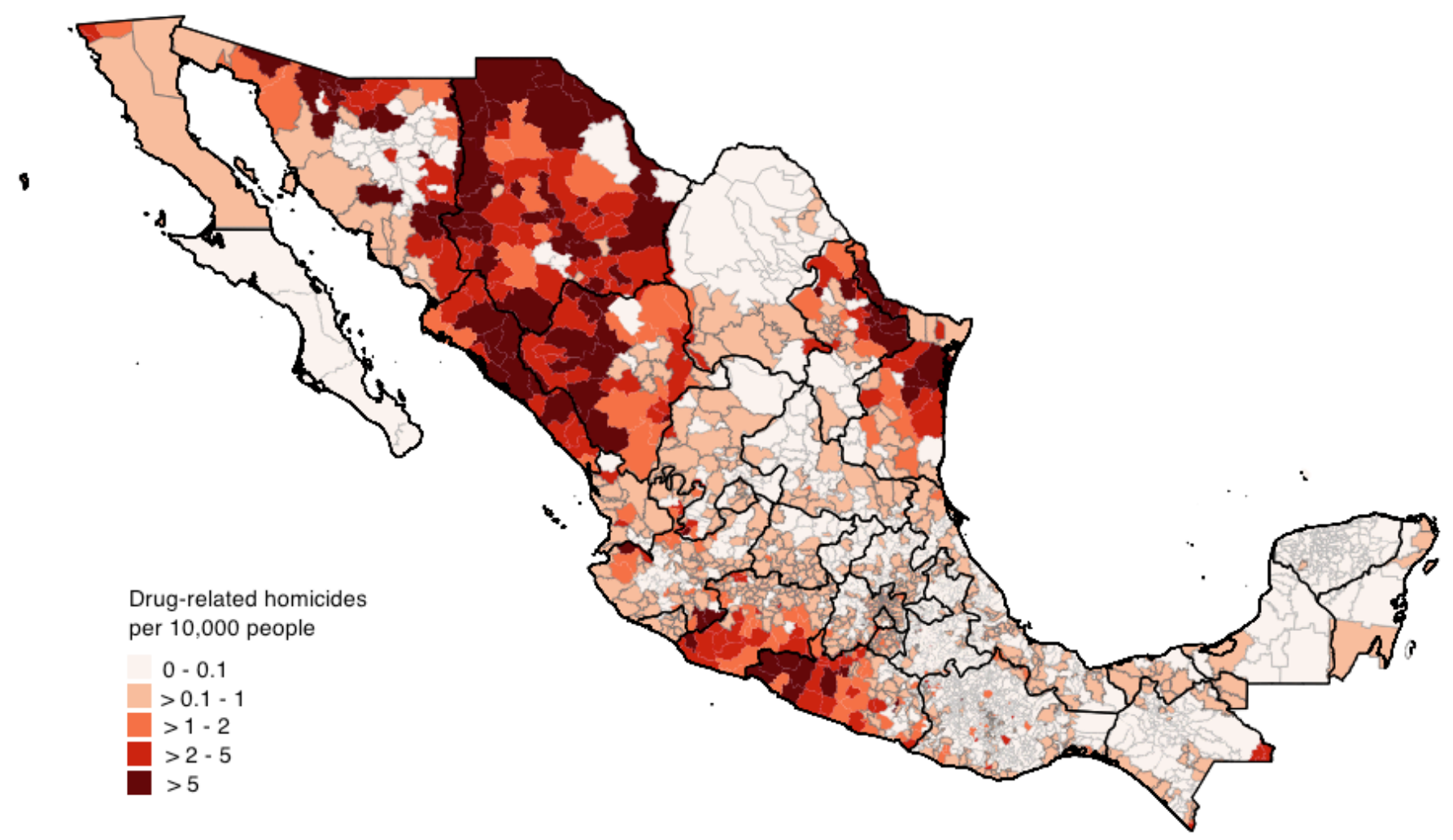

Notes: This map shows the annual average of drug-related killings per 10,000 people in each Mexican municipios between 2007 and 2010. The data come from the Mexican National Security Council. Darker colors denote higher levels of drugrelated killings. 
Figure 4: Maize Suitability

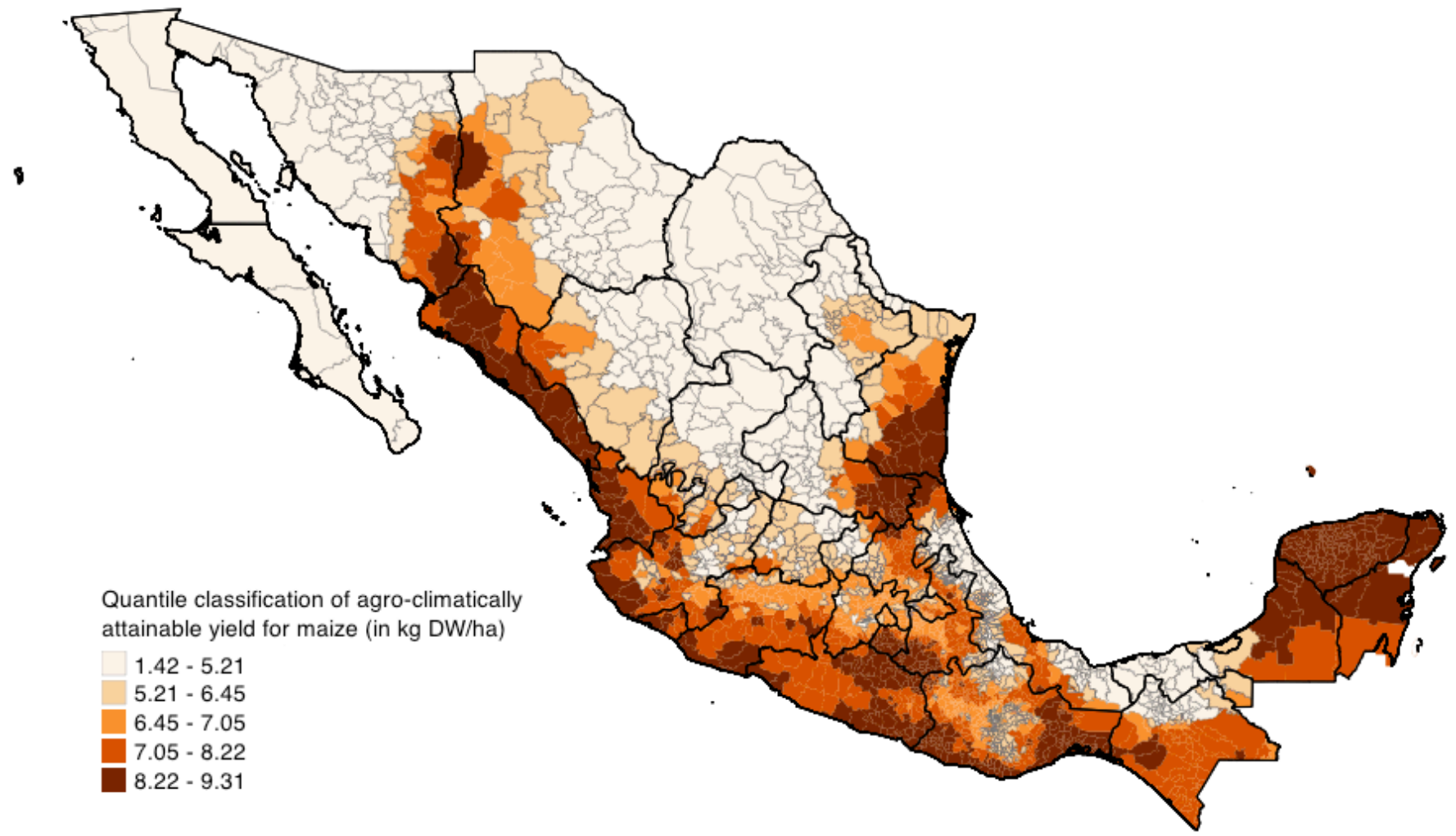

Notes: This figure shows the average agro-climatically attainable yield for maize (measured in kg DW/ha) for each Mexican municipio. This measure was constructed using 0.083-degree resolution data from the FAO's Global Agro-Ecological Zones (GAEZ v3.0). Darker colors denote higher suitability and potential yield for maize. 
Figure 5: Maize Prices, Maize Exports, and U.S. Weather Shocks
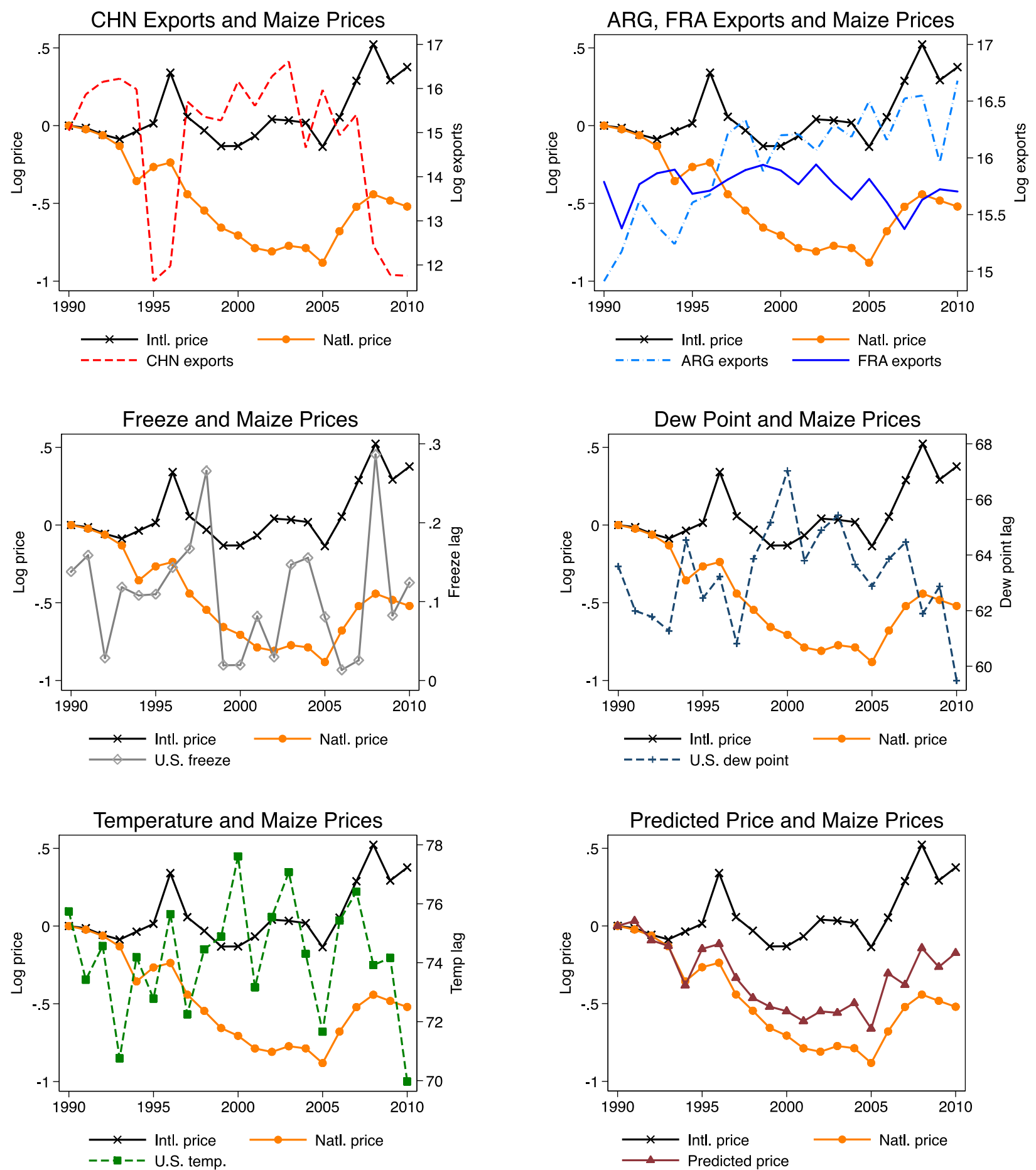

Notes: The top-left panel shows the (log) volume of maize exported by China (CHN). The top-right panel shows the (log) volume of maize exported by Argentina (ARG) and France (FRA). The center-left panel shows the lagged freeze hours in the U.S. Corn Belt. The center-right panel shows the lagged dew point in the U.S. Corn Belt. The bottom-left panel shows the lagged temperature in the U.S. Corn Belt. The bottom-right panel shows the national maize price predicted by all instruments in time series regressions. All panels also show the $(\log )$ national and international maize prices deviations from 1990 over the 1990-2010 period. 


\section{Figure 6: The Maize Price, Maize Suitability and Drug-Related Outcomes}
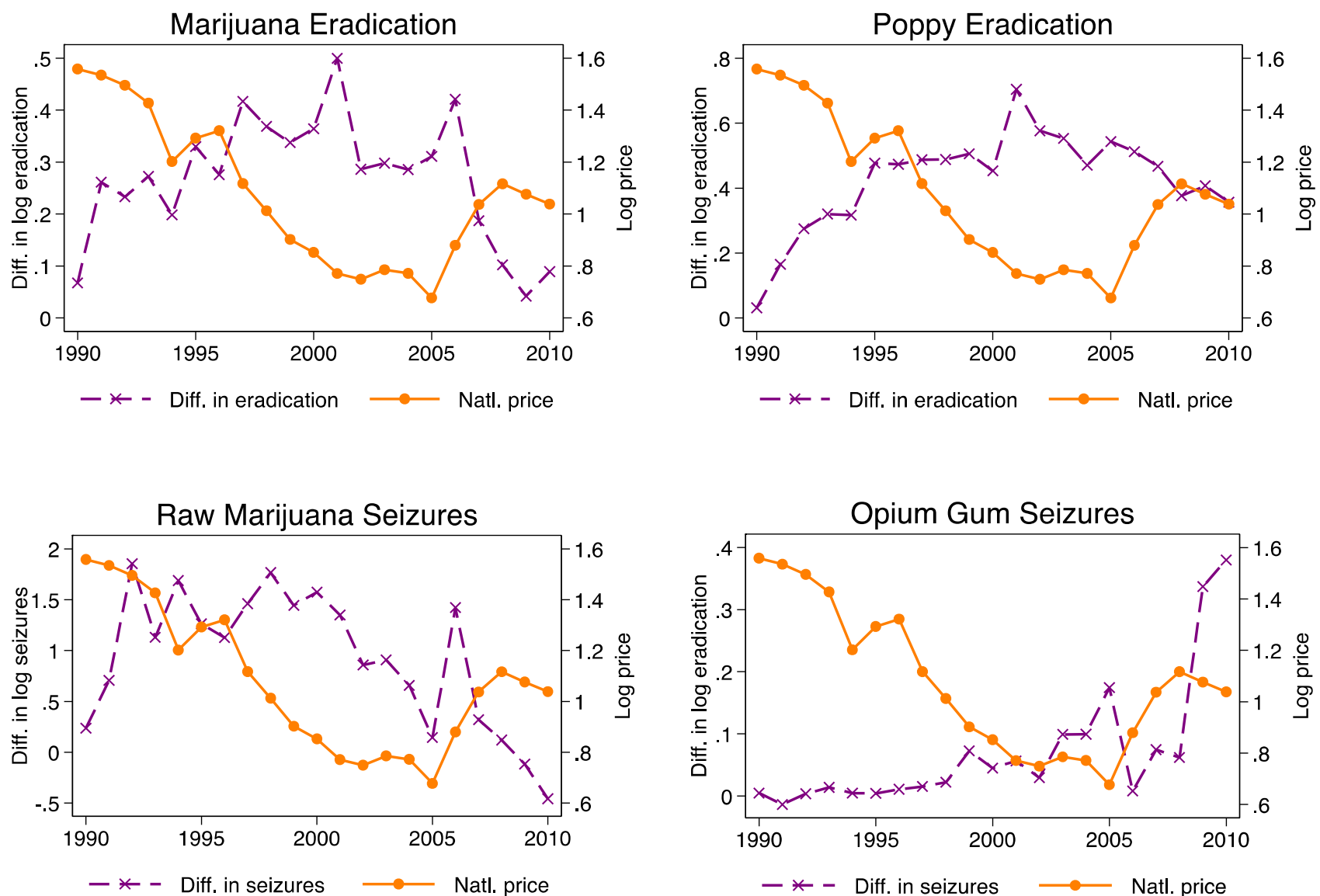

Notes: The top-left panel shows the difference in (log) average marijuana eradication in municipios above and below mean maize suitability. The top-right panel shows the difference in (log) average opium poppy eradication in municipios above and below mean maize suitability. The bottom-left panel shows the difference in (log) average opium raw marijuana seizures in municipios above and below mean maize suitability. The bottom-right panel shows the difference in (log) average opium gum seizures in municipios above and below mean maize suitability. All panels also show the (log) national maize price over the 1990-2010 period. 